\title{
Investigation of the Anti-TB Potential of Selected Alkaloid Constituents Using A Molecular Docking Approach
}

By

Zaira Zafroon

15146109

A thesis submitted to the Department of Department of Pharmacy in partial fulfillment of the requirements for the degree of

Bachelor of Pharmacy (Hons)

Department of Pharmacy

Brac University

August 2019

(C) 2019 Brac University

All rights reserved. 


\section{Declaration}

It is hereby declared that

1. The thesis submitted is my/our own original work while completing degree at Brac University.

2. The thesis does not contain material previously published or written by a third party, except where this is appropriately cited through full and accurate referencing.

3. The thesis does not contain material which has been accepted, or submitted, for any other degree or diploma at a university or other institution.

4. I have acknowledged all main sources of help.

\section{Student's Full Name \& Signature:}

\section{Zaira Zafroon}

15146109 


\section{Approval}

The thesis/project titled "Investigation of the Anti-TB Potential of Selected Alkaloid Constituents Using A Molecular Docking Approach" submitted by Zaira Zafroon (15146109) of Spring,2015 has been accepted as satisfactory in partial fulfillment of the requirement for the degree of Bachelor of Pharmacy (Hons) on 22 ${ }^{\text {nd }}$ August, 2019.

\section{Examining Committee:}

Supervisor:

Mohammad Kawsar Sharif Siam

Senior Lecturer, Department of Pharmacy

Brac University

Program Coordinator:

Dr. Hasina Yasmin

Associate Professor, Department of Pharmacy

Brac University

Departmental Head:

Dr. Eva Rahman Kabir

Professor and Chairperson, Department of Pharmacy

Brac University 


\section{Ethics Statement}

The study does not involve any kind of animal trial and human trial. 


\begin{abstract}
Mycobacterium tuberculosis, the leading bacterial killer disease worldwide, causes Human tuberculosis (TB). In this study, we used a molecular docking approach to investigate the interactions between selected alkaloids and proteins MtPanK, MtDprE1 and MtKasA involved in physiological functions which are necessary for the bacteria to survive and cause disease. The best docking scores indicates the highest ligand protein binding and specific interactions were studied to understand the nature of intermolecular bonds. Shermilamine B showed a docking score of $-8.5 \mathrm{kcal} / \mathrm{mol}$ which was higher than the standard TLM score. Brachystamide B showed a docking score of $-8.6 \mathrm{kcal} / \mathrm{mol}$ which was higher than the standard ZVT score. Monoamphilectine A showed a score of $-9.8 \mathrm{kcal} / \mathrm{mol}$ which is higher than the standard score of 0T4.These three given compounds or alkaloids had given docking scores which were superior to the control inhibitors and represent the opportunity of in vitro biological evaluation and of anti-TB drug design.
\end{abstract}

Keywords: Mycobacterium Tuberculosis; MtKasA; MtPanK; MtPknB; MtDprE1, Alkaloids. 


\section{Dedication}

Dedicated to my supervisor Mohammad Kawsar Sharif Siam. 


\section{Acknowledgement}

I would like begin by thanking the Almighty Allah, our creator, the source of our life and strength, our knowledge and wisdom, for the blessings and mercy. This research would not have been completed without the support of the people who are gratefully recognized here.

First and foremost, I would like to express my deepest gratitude and honor to my most esteemed supervisor, Mohammad Kawsar Sharif Siam, Senior Lecturer, Department of Pharmacy, and Brac University. Working under his supervision allowed me to understand and broaden my knowledge on the field of bioinformatics. Without his valuable input and supervision this project would not come to light. I am highly grateful to have had the opportunity to work under him.

I would like to express my deepest gratitude and honor to Professor Dr. Eva Rahman Kabir, Chairperson and Professor, Department of Pharmacy, Brac University, one of the finest, kindest and elegant human being I have ever come in contact with.

Last but not the least, I would like to thank my family and friends for being with me, supporting me and encouraging me work harder and harder in every phase of my life. Without their prayers and unconditional love, I would not have come this far. 


\section{Table of Contents}

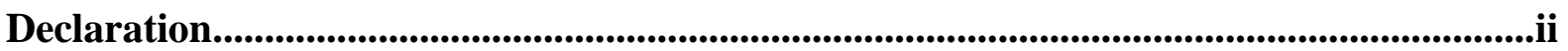

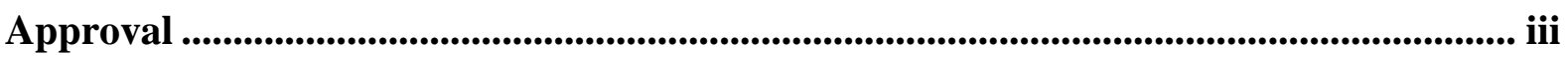

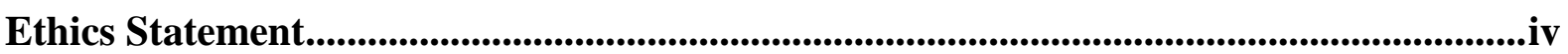

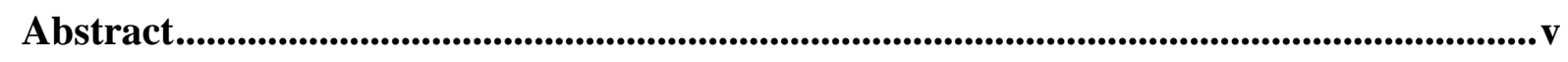

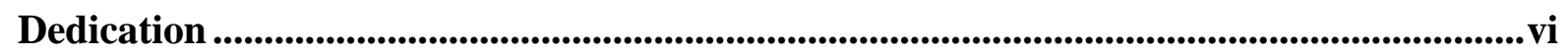

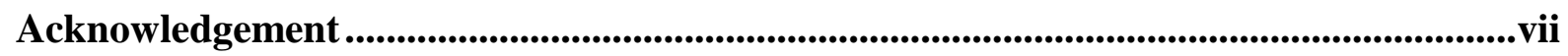

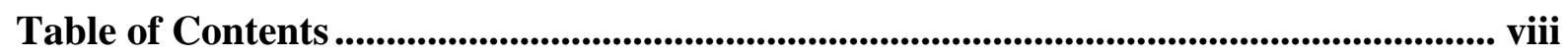

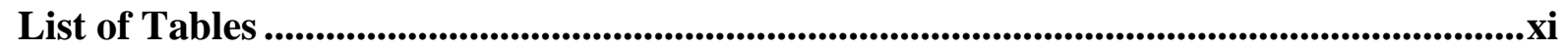

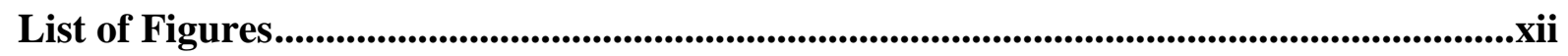

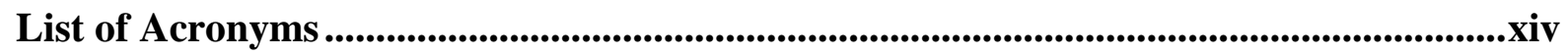

Chapter 1 Introduction..................................................................................................................1

1.1 Need for Computational Techniques for Drug Discovery ............................... 2

1.1.1 Molecular Docking Approach for Drug development ....................................

1.1.2 Auto Dock Tools and Auto dock Vina ......................................................

1.2 The Need for New Drugs for Tuberculosis..................................................

1.2.1 Plants as a source of new drug lead .........................................................

1.2.2 Alkaloids as Antimicrobial Drug leads ......................................................

1.3 Molecular Targets for Antimicrobial Agents .............................................

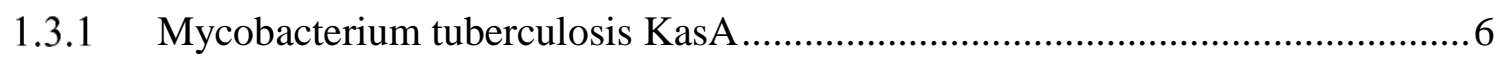

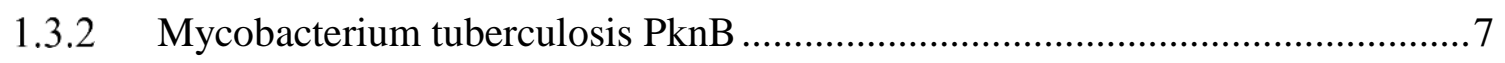




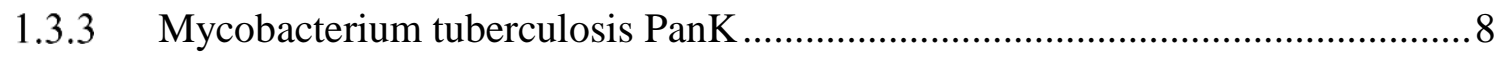

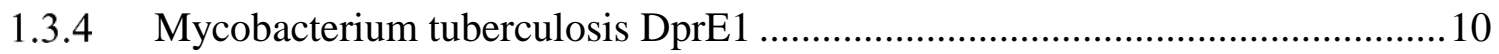

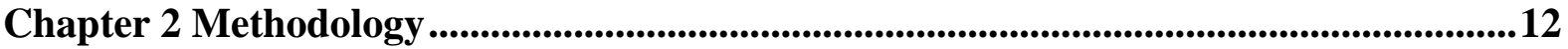

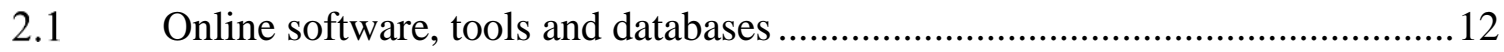

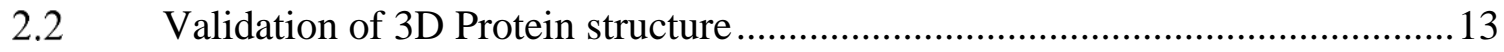

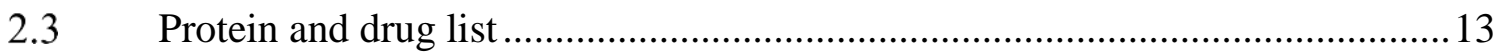

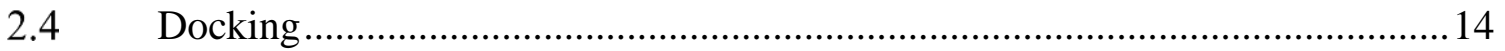

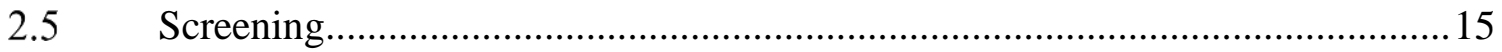

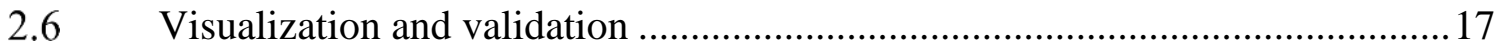

Chapter 3 Results and validation .....................................................................................18

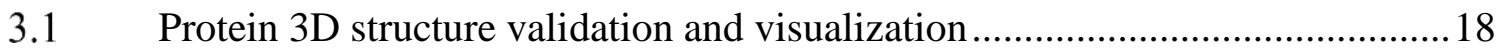

3.1.1 MtKasA 3D Structure Validation .............................................................. 18

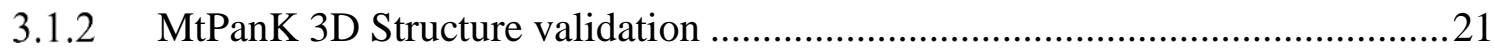

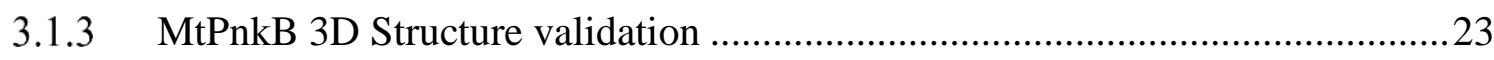

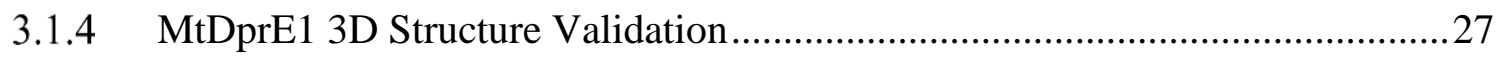

3.2 In silico binding results obtained after docking .............................................29

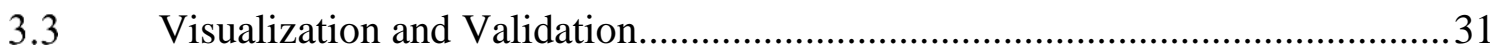

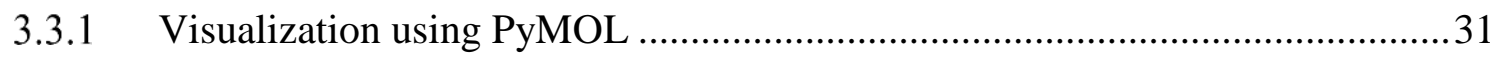

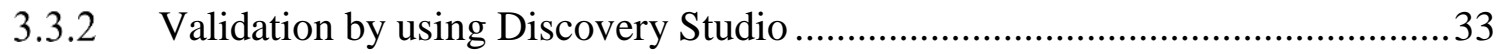

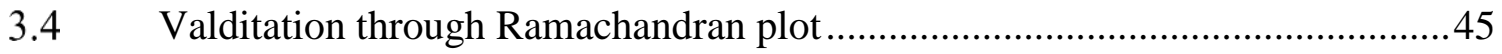

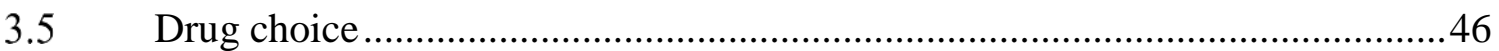


3.5.1 MtKasA (PDB ID:2WGE)

.46

3.5.2 MtPknB (PDB ID: 2FUM)

49

3.5.3 MtPanK (PDB ID: 4BFT)

.51

3.5.4 MtDprE1 (PDB ID: 4FF6)

.54

Chapter 4 Discussion

.57

Chapter 5 Conclusion

.59

Chapter 6 Future work.

.60

References.

.61

X 


\section{List of Tables}

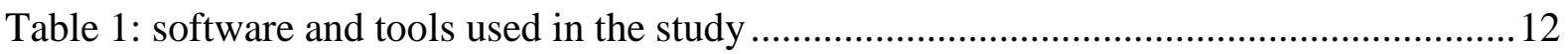

Table 2: binding affinities of proteins with alkaloid compound (proposed ligand) ................30

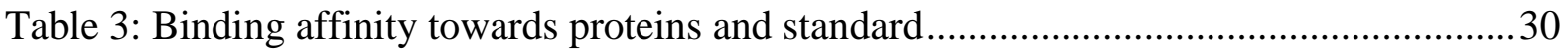

Table 4:ZVT interaction with MtPank (4BFT) ................................................................. 34

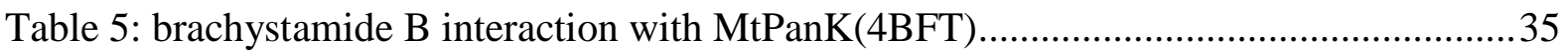

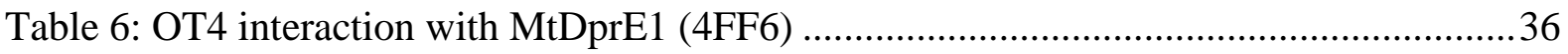

Table 7: Monoamphilectine A interaction with MtDprE1 (4FF6)...................................... 38

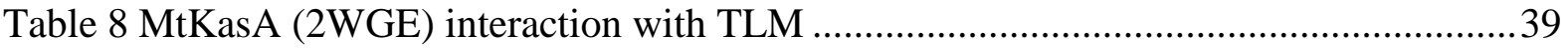

Table 9 MtKasA(2WGE) interaction with shermialmine B ............................................. 40

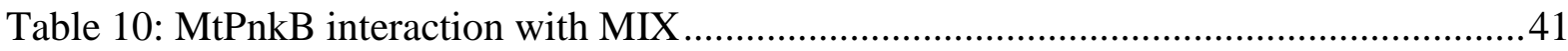

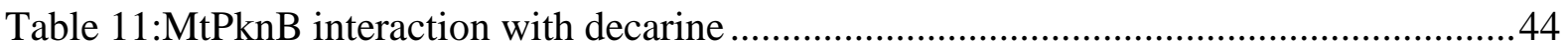

Table 12: Physiochemical properties of standard and proposed drug ................................. 46

Table 13:ADMET properties of the standard and proposed drug......................................48

Table 14-Physiochemical properties of the standard and proposed drug .............................49

Table 15:ADMET properties of the standard and proposed drug.......................................50

Table 16: Physiochemical properties of the standard and proposed drug .............................52

Table 17: ADMET properties of the standard and proposed drug ......................................53

Table 18: Physiochemical properties of the standard and proposed drug .............................54

Table 19:Physiochemical properties of the standard and proposed drugs .............................55 


\section{List of Figures}

Figure 1: Mycobacterium Tuberculosis KasA ..............................................................

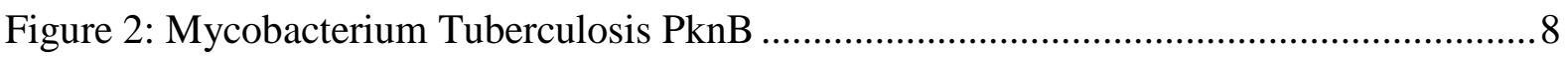

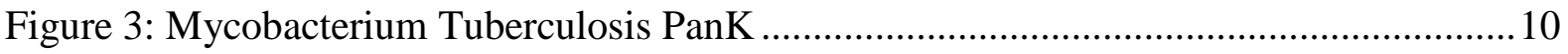

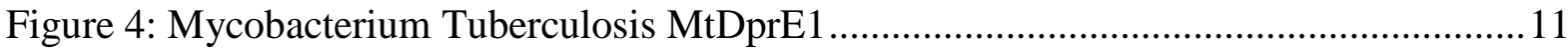

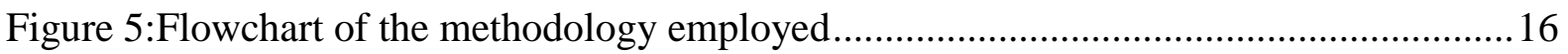

Figure 6: 3D structure of MtKasA (PDB ID-2WGE) without heteroatoms obtained from PyMol

Figure 7 The z-score (-9.45) of MtKasA (PDB ID-2WGE) obtained from ProSA Web ....... 19

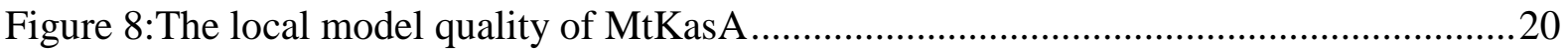

Figure 9: 3D structure of MtPank (PDB ID-4BFT) without heteroatoms obtained from PyMol

Figure 10: The z-score (-7.13) of MtPanK (PDB ID-4BFT) obtained from ProSA Web .......22

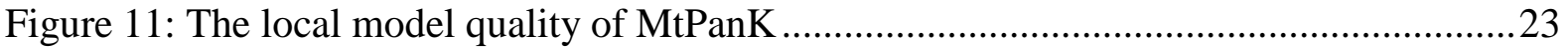

Figure 12 : 3D structure of MtPnkB (PDB ID-2FUM) without heteroatoms obtained from

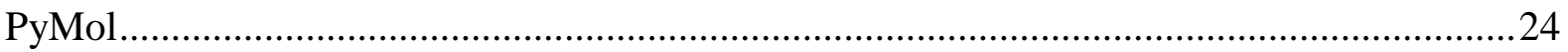

Figure 13: The z-score (-7.36) of MtKnB (PDB ID-4BFT) obtained from ProSA Web.........25

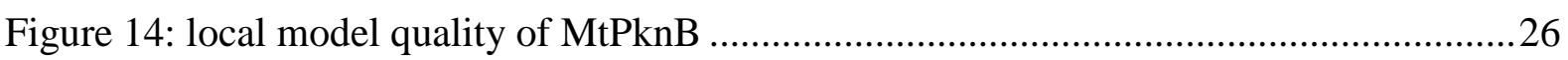

Figure 15: 3D structure of MtPnkB (PDB ID-4FF6) without heteroatoms obtained from PyMol

Figure 16: The z-score (-7.36) of MtDprE1 (PDB ID-4FF6) obtained from ProSA Web ......28

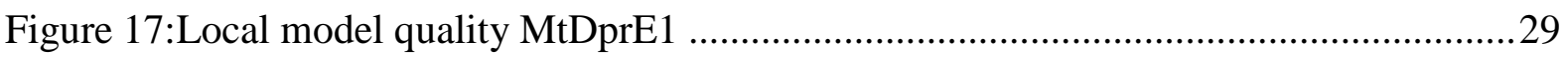

Figure 18: Superimposition of Decarine and MIX structures in the same binding pocket.......31

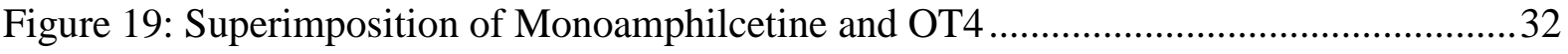

Figure 20:Bracystamide and ZVT bind to the same binding pocket …................................32 
Figure 21: Shermilamine B and TLM bind to the same binding pocket .33

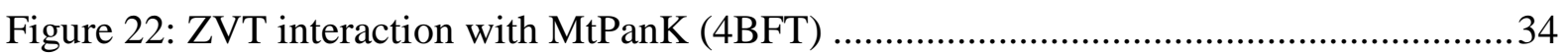

Figure 23: Brachystamide B interaction with MtPanK(4BFT) ........................................... 35

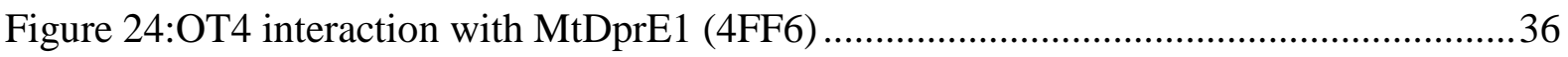

Figure 25: Monoamphilectine A interaction with MtDprE1 (4FF6) ................................... 38

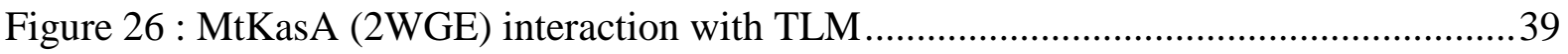

Figure 27: MtKasA (2WGE) interaction with shermilamine B ........................................ 40

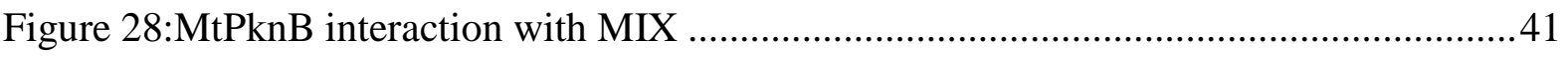

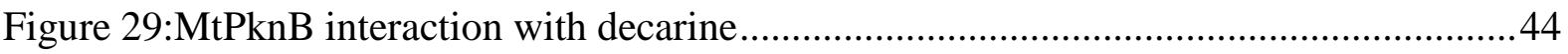




\section{List of Acronyms}

MtKasA Mycobacterium Tuberculosis Kasa

MtPknB Mycobacterium tuberculosis PknB

MtDprE1 Mycobacterium tuberculosis DprE1

MtPanK Mycobacterium Tuberculosis Pank

$\mathrm{Tb}$

Tuberculosis 


\section{Chapter 1}

\section{Introduction}

Mycobacterium tuberculosis causes a disease in humans known as human tuberculosis (TB) and it is the leading cause of death from a single infectious agent throughout the world (Bloom et al., 2017). Ten million people became ill with TB in 2017, and 1.6 million of those people died suffering from the disease ("Tuberculosis," 2018).TB rates are especially high in developing nations and together with HIV/AIDS and malaria cause an enormous burden on health care systems. Treatment of TB is a lengthy process involving complicated drug regimens with high risk of adverse drug effects and drug-drug interactions taking place and has been notorious for poor compliance in patients. It has contributed to the development of multidrugresistant strains (MDR-TB) and extensively drug-resistant strains (XDR) (World Health Organisation, 2018). The amount of potential cases of multidrug-resistant (MDR) tuberculosis (caused by at least rifampicin-resistant and isoniazid-resistant strains of Mycobacterium tuberculosis) and extensively drug-resistant (XDR) tuberculosis (Characterized by rifampicin, plus any fluoroquinolone and isoniazid, resistance and resistant to one of three second-line tuberculosis injectable drugs, capreomycin, amikacin, kanamycin) is increasing alarmingly (Seung, Keshavjee, \& Rich, 2015). MDR-TB treatment involves costly drugs and often XDRTB is untreatable. Due to the rise in resistant TB strains in the past several years, TB is now a global emergency (World Health Organisation, 2018). In spite of the fact that efforts to develop drugs have intensified in recent years, licensing two new anti-TB drugs (bedaquiline and delamanide) and currently undergoing clinical evaluations, the current drug development pipeline is still insufficient to address the current global health challenge. An urgent need remains to discover new drug remains, especially that can target resistant TB strains (Kana, Karakousis, Parish, \& Dick, 2014). By shortening the timer required for generation of newer 
chemical scaffolds will positively affect the likelihood of clinical success of a drug candidate so that a comprehensive approach for drug discovery can be made (Kaur et al., 2017).

\subsection{Need for Computational Techniques for Drug Discovery}

It is generally recognized that the process of discovery and development of new drugs is timeconsuming, risky and costly. From concept to market ,the typical drug discovery and development cycle takes roughly 14 years (Myers \& Baker, 2001), and the expense falls between $\$ 0.8$ billion to $\$ 1.0$ billion (Moses, Dorsey, Matheson, \& Thier, 2005). Rapid advances in combinatorial chemistry and high-throughput screening technologies have created an atmosphere for accelerating drug discovery cycle by allowing large chemical databases to be examined and synthesized in a short period of time (Lahana, 1999) (Lobanov, 2004).Even though expenditure in the development of new drugs has grown significantly over the past decades, the output is not positively proportional to the investment given the low efficiency and high rate of drug discovery failure(Shekhar, 2008). As a result, different approaches were developed to shorten the research cycle and reduce the drug discovery expense and risk of failure. One of the most effective methods to achieve these goals is computer-aided drug design (CADD) (Ou-Yang et al., 2012).

\subsubsection{Molecular Docking Approach for Drug development}

Protein-ligand or protein-protein docking plays a key role in predicting the ligand's orientation when bound to a receptor or enzyme by quantifying three-dimensional shape and electrostatic interactions in case of modern process of drug discovery. Besides Coulombic interactions and the formation of hydrogen bonds, the van der Waals interactions also play an important role. A docking score, represents binding potentiality and gives an approximation of the sum of all these interactions. In the clearest rigid body systems, the ligand is searched for fitting the 
binding site in a six-dimensional rotational or translation space that can serve as a lead compound for drug design (Alberg \& Schreiber, 1993).

\subsubsection{Auto Dock Tools and Auto dock Vina}

To predict binding nature of small, flexible ligand with known 3D structure target, a free suite of docking programs known as Auto Dock is used. To set up the experiment and to analyze the docking experiment the front-end graphical interface of AutoDock Tools is used. After which ' auto dock ' carries out the docking calculations of ligand to the target protein, represented by a set of grids pre-calculated by “auto grid”. Monte Carlo simulated annealing method was used' in older software versions (versions 2.4-4.0) to search for ligand conformations and energy was evaluated by a grid based approach (Goodsell, Morris, \& Olson, n.d.). Based on energy similarity, using a genetic algorithm, a series of docking poses are generated and clustered. Interestingly, researches have demonstrated that the most populated cluster best calculates the docked ligand's native state(Källblad, Mancera, \& Todorov, 2004;Limongelli et al., 2007).

In favor of knowledge-based scoring, an offshoot of the original program, called Auto Dock Vina, eliminated the empirical scoring function and the genetic energy algorithm clustering of former versions. This is achieved through the Monte Carlo sampling and the Broyden-FletcherGoldfarb-Shanno method for local optimization. Auto Dock Vina has significantly improved both predictability and time required for docking (Trott \& Olson, 2010).

\subsection{The Need for New Drugs for Tuberculosis}

Tuberculosis (Tb), primarily caused by Mycobacterium tuberculosis (Mtb), is a major disease that affects millions of people each year with high mortality rates. The lack of treatment options accompanied by the current emergence of MTB's multi-drug resistant (MDR) and extreme drug resistance (XDR) strains (Paulson, 2013;Global tuberculosis report, 2014) remains a barrier in solving this problem(Koul, Arnoult, Lounis, Guillemont, \& Andries, 2011;Cohen, Lobritz, \& 
Collins, 2013).There are a low number of drugs available for the treatment of Tb (MDR / XDR) and there are several reasons for the lack of new drugs, including the lack of funding for such neglected diseases in Pharmaceutical Research \& Development. Drug development's prohibitive cost has been caused by poor target selection and as a result, 87 percent of latestage failures can be avoided as they show poor effectiveness and negative effects (Munos, 2009). In the current situation, understanding an organism's complex biological responses or system biology is highly important in improving and speeding up the drug development process by decreasing the rate of failures. Based on knowledge about existing lead compounds which work against Mtb, methods of selective chemical molecular customization have the ability to fuel the $\mathrm{Tb}$ clinical pipeline and address the issue of the rise of resistant strains. Innovative approaches to developing new chemical entities such as using data intensive in silico approaches can minimize the cost associated with failure of drug in late stages and increase the speed at which new drugs are made available in the market.

\subsubsection{Plants as a source of new drug lead}

Plants are found mostly on lands but they could be found in every habitable environment. In the face of stresses and challenges plants have developed numerous molecules to prevent or stop animal attacks and adapt to environmental changes(Weng, Philippe, \& Noel, 2012). Historical findings and reports show that plants were used in earlier era for medical purposes (Lietava, 1992). For anticancer and antimicrobials drugs in particular, natural products have been the go to source of dug compounds (HARVEY, 2008;Harvey, Clark, Mackay, \& Johnston, 2010;Chang, Kim, \& Kwon, 2016) . A number of researchers have highlighted the urge to discover and develop new antitubercular drugs to reduce the burden of deadly disease, also known as "Captain of Death,"(B. B. Mishra \& Tiwari, 2011;Zumla, Nahid, \& Cole, 2013). 


\subsubsection{Alkaloids as Antimicrobial Drug leads}

The lessons learned from current efforts to generate TB hits and newly validated drug targets for TB can now be applied to generate new TB drugs. Using currently underexploited chemicals sources and lead-optimization methods can improve the efficiency of drug development process. Mdluli discusses probable leads for the development of antimicrobial drugs in his review (Mdluli, Kaneko, \& Upton, 2014). Various plant extracts were commonly used in traditional medicine for the treatment of tuberculosis and there is a renewed interest in plants as a source of new drug development (Dashti, Grkovic, \& Quinn, 2014).There is research that proves alkaloids have wide therapeutic applications and can be an ideal target for drug development as researches are being done to develop new drugs from natural sources for tuberculosis (S. K. Mishra et al., 2017). Decarine, a benzophenanthridine alkaloid, was extracted from Zanthoxylum capense and showed significant antimycobacterial activity against $\mathrm{H} 37 \mathrm{Rv}$ strains of $\mathrm{M}$. Tuberculosis at the minimum inhibitory concentration at 3.1mg/mL (Luo et al., 2013). Extracts from Diplosoma and sea squirts lissoclinum showed the presence of an alkaloid called shemilamine B and inhibits the growth of tuberculosis at the MIC value of mM (Appleton, Pearce, \& Copp, 2010). An alkyl amide named brachystamide B, has been extracted from Piper Sarmentosum and has showed moderate inhibitory activity against M. Tuberculosis at the MIC value of $50 \mathrm{mg} / \mathrm{mL}$ (Isaka, Boonkhao, Rachtawee, \& Auncharoen, 2007). Monamphilectine A (diterpenoid b-lactam alkaloid ) isolated from the Hymenia cidon marine sponge, at MIC value of $15.3 \mathrm{mg} / \mathrm{mL}$ showed potent antimycobacterial properties (Avilés \& Rodríguez, 2010) .

\subsection{Molecular Targets for Antimicrobial Agents}

Antimycobacterial medications have bactericidal properties which inhibits the M. TB and have bacteriostatic abilities which averts M. TB's growth. Different molecular targets for existing 
antitubercular drugs are well known. The targets chosen to identify novel leads are specific to preventing mutated gene transfer from one generation to another. The novel compound should be active throughout M.TB's lifecycle (Zhang, Post-Martens, \& Denkin, 2006). The target molecules can be either inside or outside of the mammalian cells and different biosynthetic pathways such as bacterial protein synthesis, cell wall and nucleic acid synthesis pathways can be included as targets for antitubercular drugs. Discovery of new drug and development of lead molecule focuses on specific target sites and they can be either bacteriostatic or bactericidal (Manjunatha \& Smith, 2015).

\subsubsection{Mycobacterium tuberculosis KasA}

The lipid-rich, highly impermeable cell wall is essential in the survival of the pathogen. (Daffé \& Draper, 1998; Yuan, Zhu, Crane, \& Barry, 1998). The long-chain mycolic acids, $\alpha$-alkyl- $\beta$ hydroxy fatty acids, constitute up to 60 percent of the cell wall and are primarily accountable for the waxy cell envelope's low permeability. Contrary to other bacteria, the layer is synthesized by two distinct pathways for fatty acid synthesis. The mammalian-like FAS and the bacteria-Like FAS-II pathway are there in the mycobacteria and play an essential role in the synthesis. (Barry et al., 1998) . (Kremer et al., 2002). The mycobacterial $\beta$-ketoacyl ACP synthase known as KasA plays a key role in the FAS-II system. KasA is essential for mycobacteria: cell lysis is induced by conditional depletion of KasA (Bhatt, Kremer, Dai, Sacchettini, \& Jacobs, 2005) and hybridization of the transporon site has shown that KasA plays a key role in survival of the pathogens. (Sassetti, Boyd, \& Rubin, 2003). 


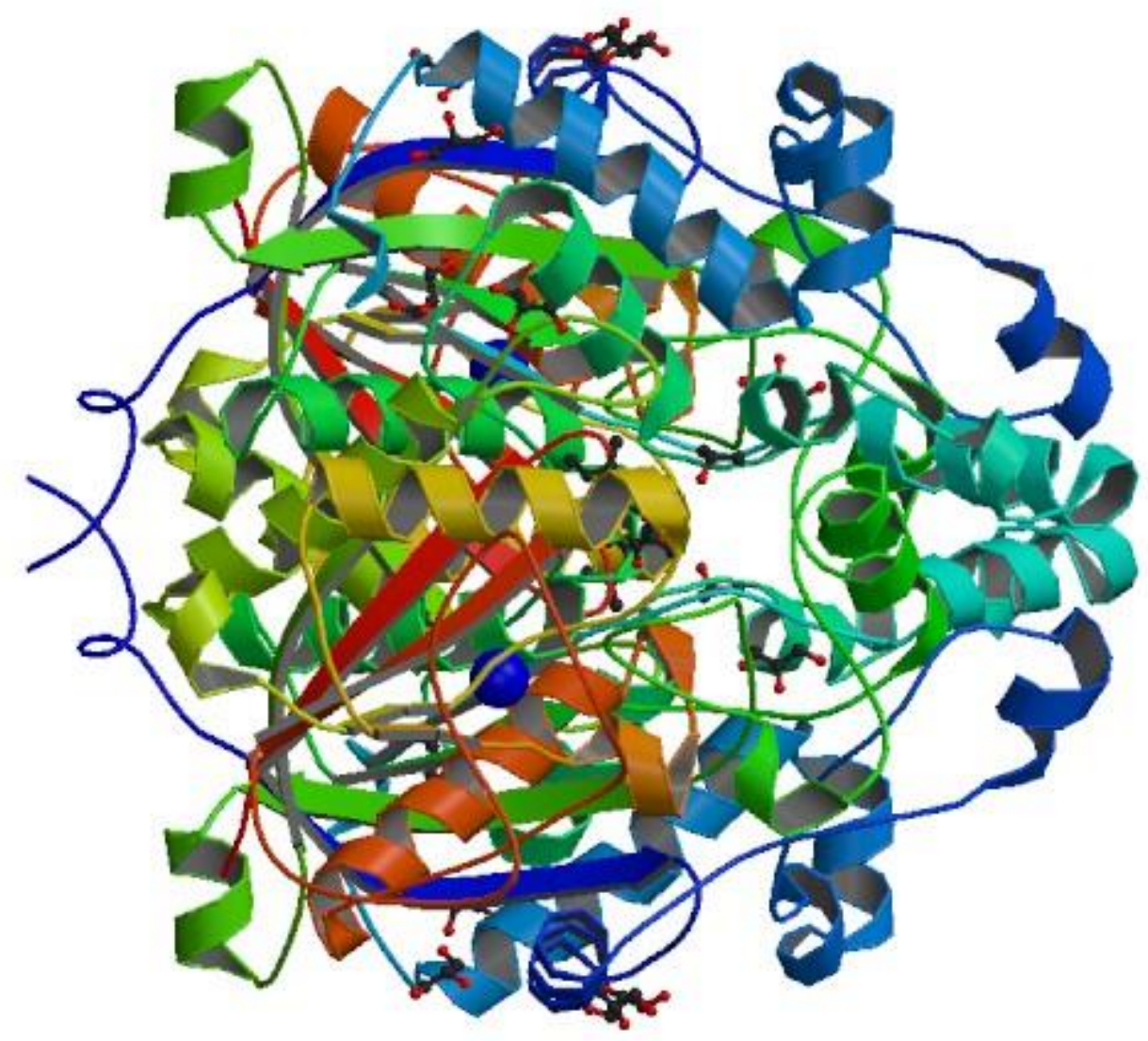

Figure 1: Mycobacterium Tuberculosis KasA

The figure depicts Mycobacterium Tuberculosis KasA.

\subsubsection{Mycobacterium tuberculosis PknB}

Mycobacterium tuberculosis $\mathrm{PknB}$, receptor like protein kinase, is vital for cell growth control in mycobacteria. To ensure tight cell growth and division regulation, mycobacteria employs reversible phosphorylation of serine / threonine residues which is a well-established process in 
eukaryotic signaling networks (Hunter, 2000). M. Tuberculosis PknB is a highly preserved trans-membrane Ser / Thr protein kinase (STPK) in gram-positive bacteria and provides mycobacteria with viability (Sassetti et al., 2003). Researches have previously demonstrated that PknB is controlled by autophosphorylation and dephosphorylation by the Ser / Thr protein phosphatase PstP (Boitel et al., 2003; Villarino et al., 2005). Additionally, recent work has shown that PknB is primarily expressed during exponential growth phase. During this phase it's overexpression causes morphological changes which are associated with synthesis of cell wall (Kang et al., 2005).

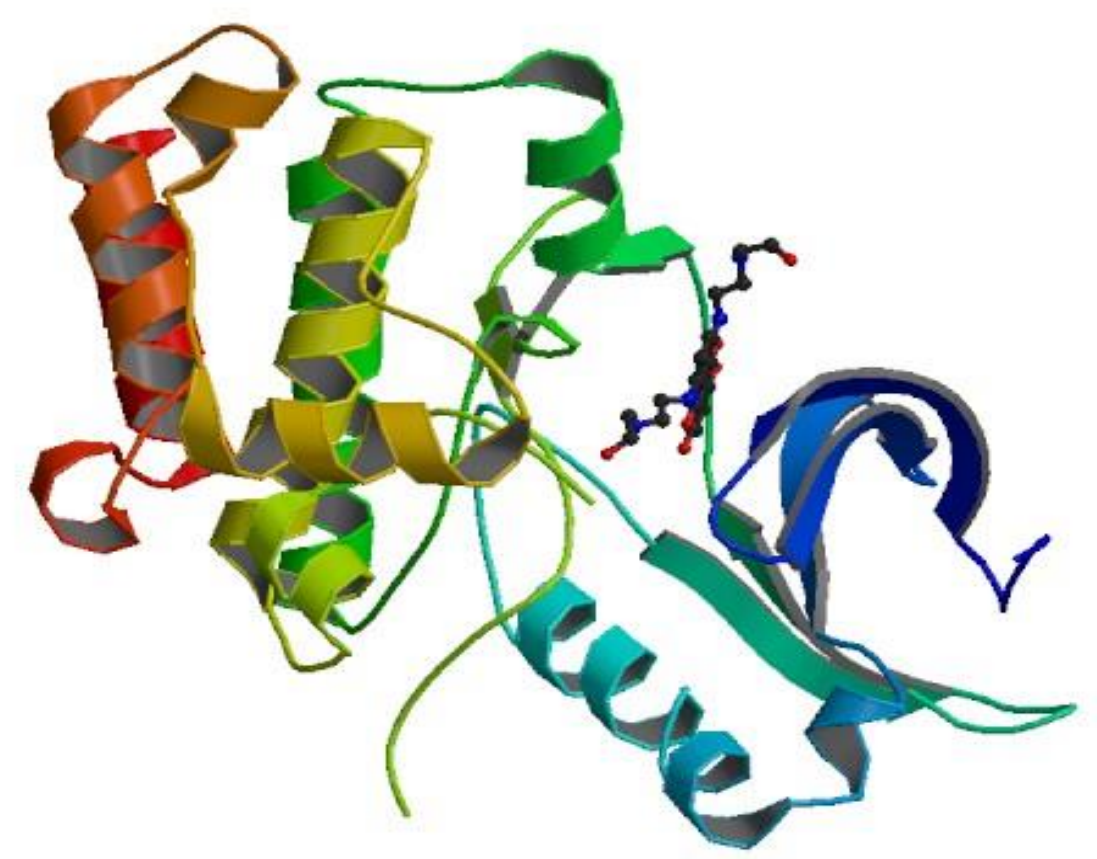

Figure 2: Mycobacterium Tuberculosis PknB

The figure depicts Mycobacterium Tuberculosis PknB.

\subsubsection{Mycobacterium tuberculosis PanK}

The universal CoA biosynthetic pathway's, pantothenate (vitamin B5) is turned to 4'phosphopantothenate using ATP as a cofactor, first and rate-limiting step is catalyzed by Pantothenate kinase (PanK, 2 EC 2.7.1.33.) (Jackowski \& Rock, 1981). Three PanK types that 
differ in their biochemical and structural characteristics have been described. CoA gene encoded type I (Dunn \& Snell, 1979), is found in many bacterial species and is tightly feedback regulated by CoA and its thioesters (Vallari, Jackowski, \& Rock, 1987). The widely researched Escherichia coli PanK are an example of this(Song \& Jackowski, 1994; Yun et al., 2000). Most of the type II enzymes are found in eukaryotes. Four isoforms of the enzyme are expressed in humans namely PanK1 to 4 . PanK2 gene defects were associated with neurodegenerative disease (Zhou et al., 2001; Rock, Karim, Zhang, \& Jackowski, 2002). Some pathogenic enzymes, such as Staphylococcus aureus PanK, are also categorized as type II enzymes on the basis of sequence and structural homology. The S. aureus enzyme is not feedback regulated but Eukaryotic PanKs are (Leonardi et al., 2005). CoaX gene encodes type III enzymes which is the most common type of enzyme amongst 12 of the 13 major groups of bacteria (K. Yang et al., 2006). It is not inhibited by CoA or its thioesters Neither CoA nor its thioesters inhibit it (Brand \& Strauss, 2005). Several bacteria have two PanK genes coding for various enzyme types. The genome of M. tuberculosis contains both coo and coax genes, which code for type I and type III PanK. However, coaA has been shown to be the only PanK gene essential for in vitro and in vivo bacterial growth (Awasthy et al., 2010). 


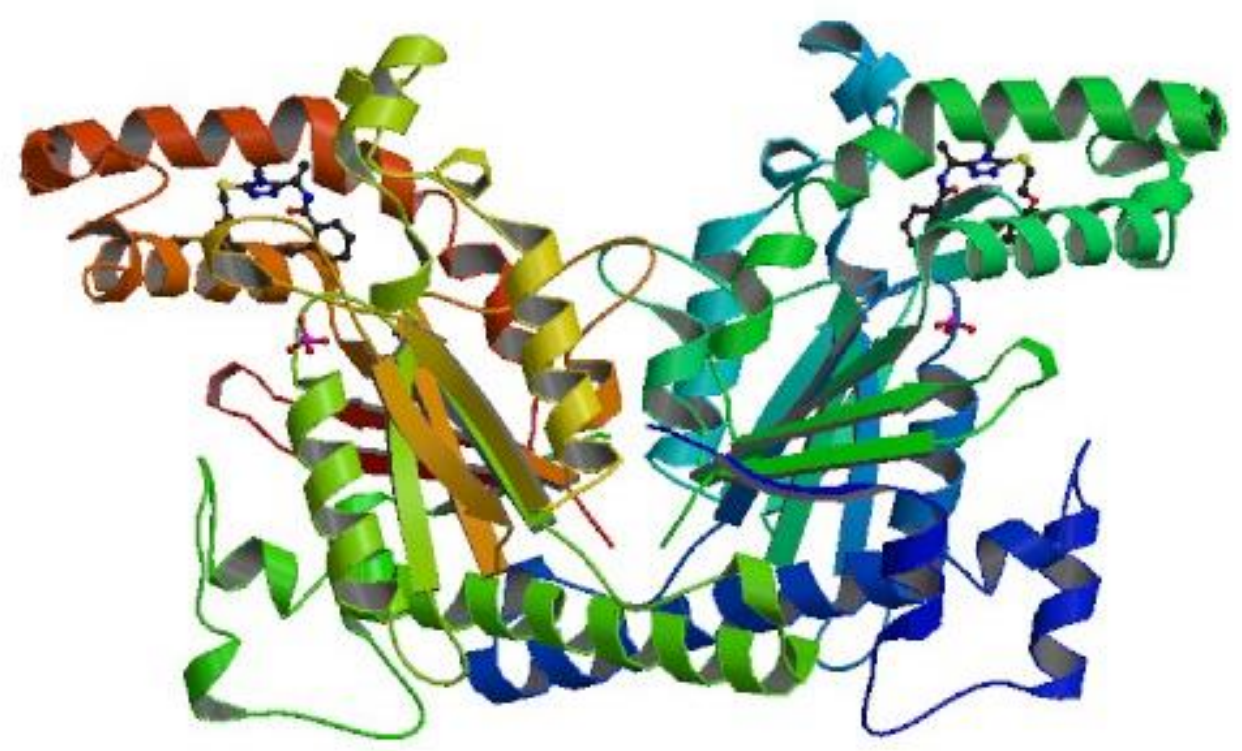

Figure 3: Mycobacterium Tuberculosis PanK

The figure depicts Mycobacterium Tuberculosis PanK.

\subsubsection{Mycobacterium tuberculosis DprE1}

Arabinan is a fundamental part of the pathogen's cell wall. Decaprenylphosphoryl arabinose, the single donor of arabinosyl residues for the buildup of arabinans is catalyzed by a unique epimerization reaction by the Mycobacterial enzyme DprE1 and DprE2 (Mikusová, Makarov, \& Neres, 2014). 


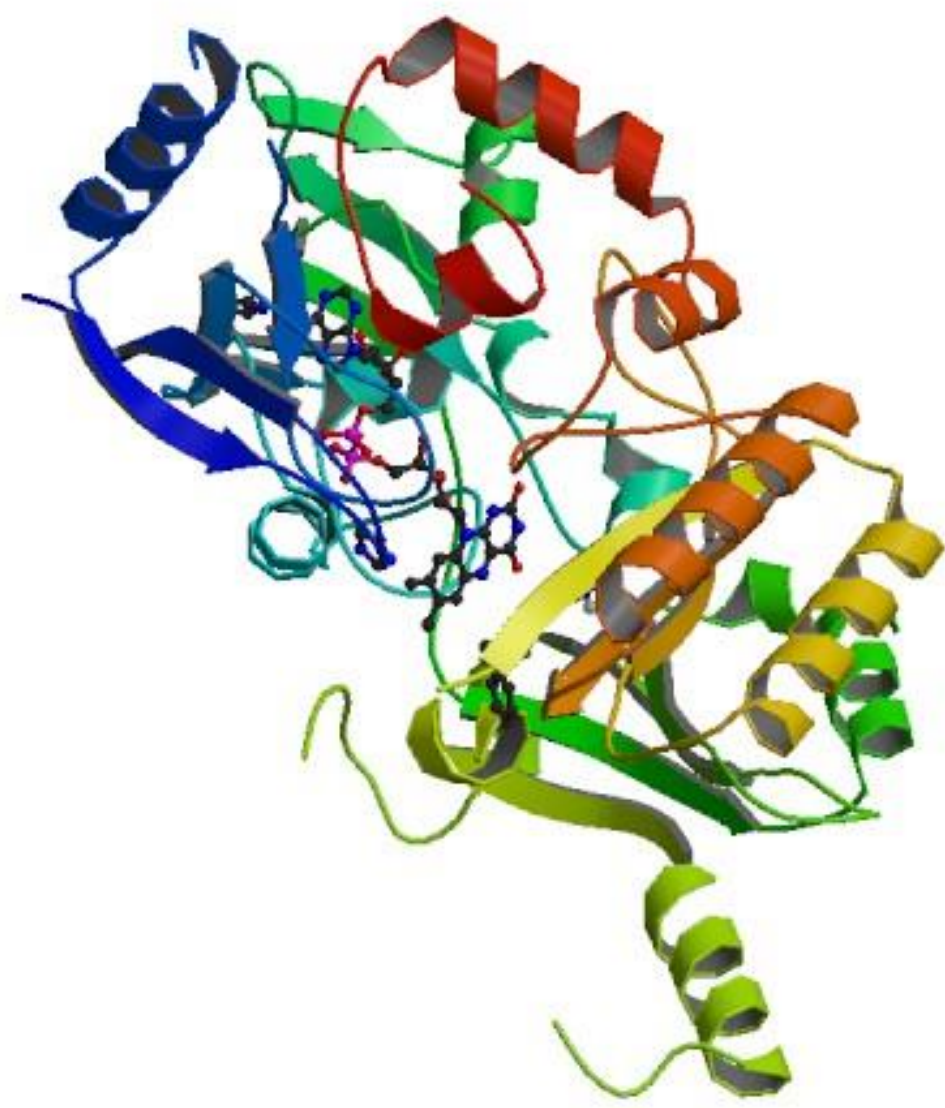

Figure 4: Mycobacterium Tuberculosis MtDprE1

The figure depicts Mycobacterium Tuberculosis MtDprE1. 


\section{Chapter 2}

\section{Methodology}

In this in silico study, potential of several anti-tuberculosis drugs chemical constituent across four different drug classes were studied using molecular docking and computational techniques. Firstly, an extensive literature study was undertaken to determine the potential target protein in Mycobacterial Tuberculosis and potential chemical constituents used in folk medicine around the world. After the initial protein target and chemical constituent list was established, and then by using molecular docking binding affinity was established between the druggable protein and chemical constituent. Three-dimensional structures of the macromolecule and ligand or chemical constituents were taken from RCSB PDB and Pubchem. For designing, the study several articles were taken from multiple Scopus index article and the study were designed based on those.

\subsection{Online software, tools and databases}

First step was to check the 3D structure of the proteins MtKasA, MtPknB, MtPanK and MtDprE1, Prossess (Berjanskii et al., 2010) and PROSESS (Berjanskii et al., 2010). Few online databases such as RCSB-PDB (Protein Data Bank) (Berman et al., 2000) PubChem (Kim et al., 2016) Drug Bank (Wishart et al., 2018a), NCBI( Geer et al., 2009) were used.

Table 1: software and tools used in the study

\begin{tabular}{|l|l|l|}
\hline Sl. & Software and tools used & Version \\
\hline 01. & Open Babel & 2.4 .1 \\
\hline 02. & PyMOL & 2.0 .4 \\
\hline 03. & AutoDock Vina & 1.1 .2 \\
\hline 04. & AutoDock tools & 1.5 .7 \\
\hline 05. & BIOVIA Discovery Studio Visualizer & 17.2 .0 .16349 \\
\hline 06. & ADMETSAR & 2.0 \\
\hline
\end{tabular}


Table 1 contains the software and tools that were used throughout the study for several purposes.

\subsection{Validation of 3D Protein structure}

The 3D structure of the protein, MtKasA (PDB ID: 2WGE) (Luckner, Machutta, Tonge, \& Kisker, 2009), MtPknB (PDB ID: 2FUM) (Wehenkel et al., 2006) MtPanK (PDB ID: 4BFT) (Björkelid et al., 2013) and MtDprE1 (PDB ID: 4FF6) (Batt et al., 2012) was obtained in a PDB format from RCSB Protein Data Bank (Berman et al., 2000). Then a visualization tool named PYMOL (DeLano, 2002) was employed to curate the heteroatoms. The curated protein structures were then verified in PROSAWEB (Wiederstein \& Sippl, 2007) and Prossess (Berjanskii et al., 2010).

\subsection{Protein and drug list}

After the validation and curation of the proteins, the structures were then ready for docking. Firstly AutoDock Tools (Morris et al., 2009) was used to change the polarity of the four protein structures by adding polar hydrogens to it using the Edit section of AutoDock Tools. To prepare the proteins for Autodock Vina, coordinates for specifying the area within the protein was specified using the 'Gridbox' from the Grid menu of ADT. After perfectly positioning the 'Gridbox' onto the protein so that it covered the whole protein, the protein was saved as 'Protein.pdbqt' in the previously created docking folder of the computer. The protein was then ready for docking using Autodock Vina (Trott \& Olson, 2010).

150 chemical constituents were chosen on the basis of different studies of their pharmacological properties and they were retrieved from both PubChem $(\mathrm{Li}$, Cheng, Wang, \& Bryant, 2010) and DrugBank (Wishart et al., 2018b). In PubChem, all the chemical structures are available in SDF format. SDF format is not compatible with AutoDock or PyRx as there is no input option for SDF files. Thus, Open babel, a free online toolbox was used to convert SDF 
format into the required PDB format (O’Boyle et al., 2011). However, drugs retrieved from DrugBank were already available in PDB format so no conversion procedure was required for them. All of the converted chemical constituents were saved in a folder for further docking procedures. The obtained drugs were then taken into AutoDock toolbox and the rotatable bonds of chemical constituents were made flexible and rigid by using the 'Torsion tree' option from the tool menu under set torsions tab. This ligand preparation step is only applicable when docking is done by using AutoDock unlike PyRx where all these are done by the software.

\subsection{Docking}

The prepared. pdbqt format of the protein and chemical constituents were then taken into autodock vina. After which a config file was prepared in the following format for each protein and each ligand.

Receptor $=$ protein. pdbqt

Ligand =ligand. pdbqt

center_x $=$ as in the grid

center_y $=$ as in the grid

center_z $=$ as in the grid

size_ $\mathrm{x}=$ as in the grid

size_y $=$ as in the grid

size_z $=$ as in the grid

Out = ligand_vina. pdbqt

After the configuration file was made, it was then transferred to the folder were auto dock vina files were saved. The protein and the ligand. pdbqt files were also saved there. After which, 
using the cmd files autodock vina was run and the binding affinities were obtained (Trott \& Olson, 2010).

\subsection{Screening}

After the docking score was obtained, the best results were chosen for further steps. Best results contained nine best binding affinities represented as negative value as it accounts for exothermic reaction. The more negative value represents superior results 


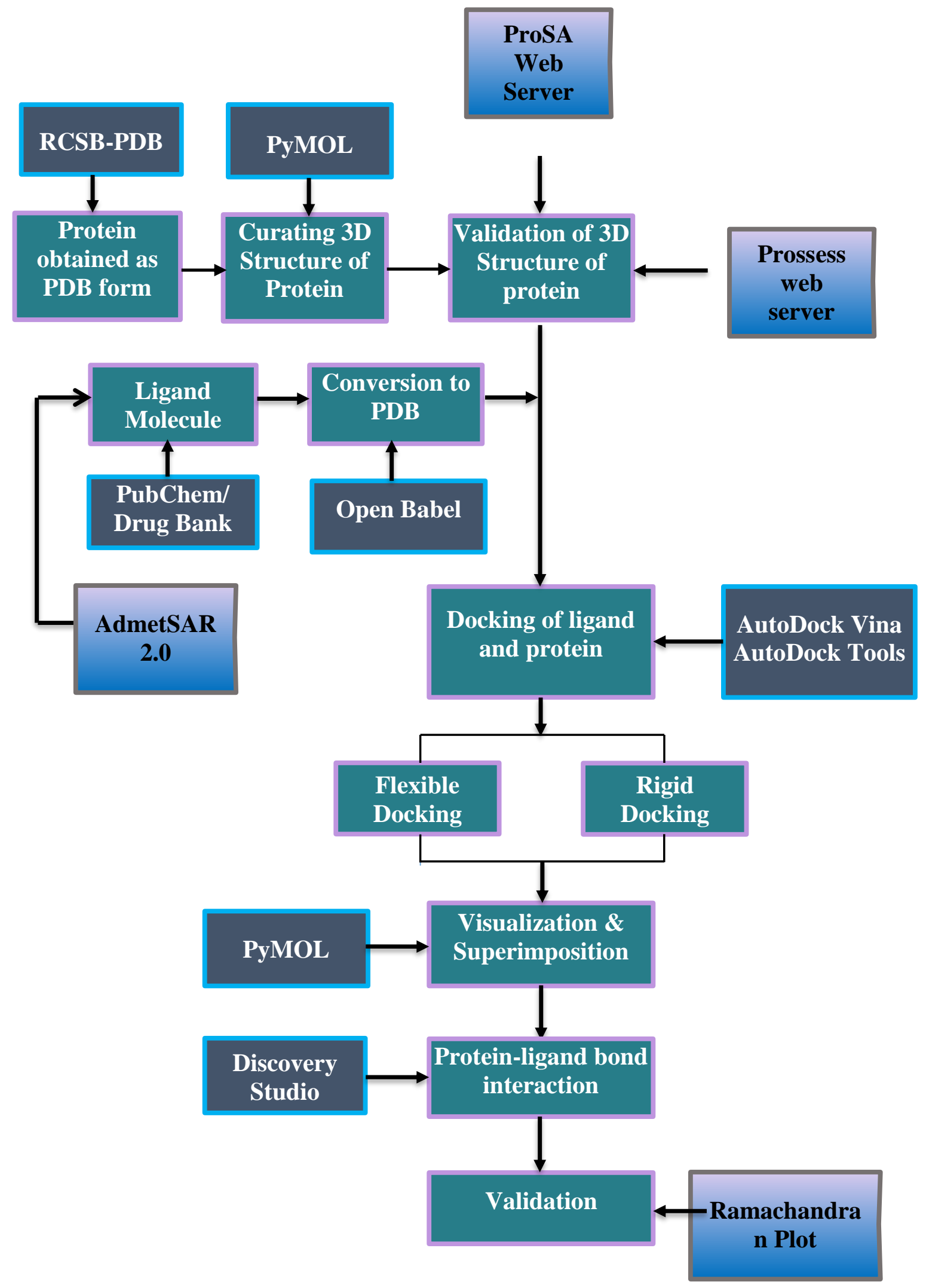

Figure 5:Flowchart of the methodology employed 


\subsection{Visualization and validation}

The output files (.pdbqt) obtained after docking were saved in a separate folder and the binding affinities were saved in a separate sheet. The 'pdbqt' files of the ligands were visualized with the four protein structures in PyMOL to see the binding site of ligands within the protein. The files were then saved for further validation using Discovery Studio Visualizer (Dassault Systèmes BIOVIA, 2010). By using Discovery studio, the protein-ligand interactions including exact amino acids, bonds and distances between bonds, were observed for each protein and ligand. After that, admetSAR 2.0 (K. Yang et al., 2006) was used to gain insights in the pharmacological properties of the proposed drug. 


\section{Chapter 3}

\section{Results and validation}

The 3D structure of the proteins MtKasA, MtPknB, MtDprE1and MtPank validation, binding affinities after docking, ADMET properties, visualization and validation are discussed in this section.

\subsection{Protein 3D structure validation and visualization}

The 3D structures of proteins are validated through different software.

\subsubsection{MtKasA 3D Structure Validation}

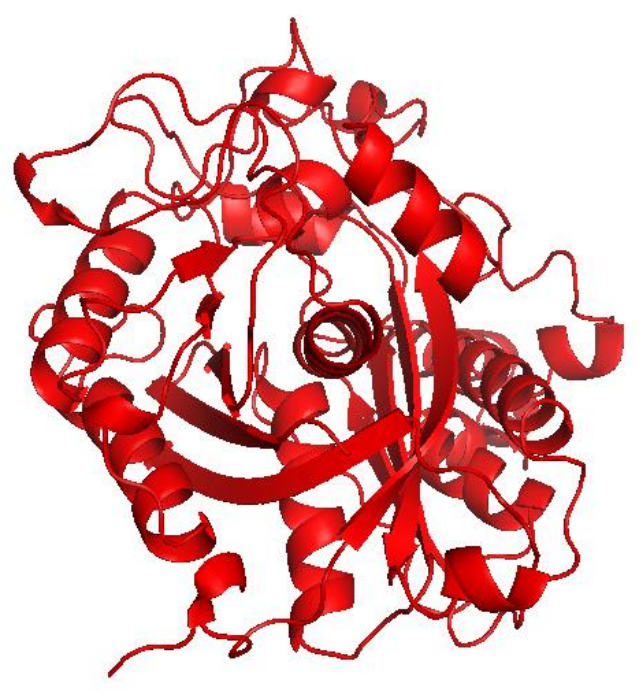

Figure 6: 3D structure of MtKasA (PDB ID-2WGE) without heteroatoms obtained from PyMol

The above figure shows the 3D structure of MtKasA on a visualizing tool named PyMOL. The alpha helix and beta sheet of the protein MtKasA can be visualized in this tool. 
In order to determine the three-dimensional structure quality of the protein, ProSA (Protein Structure Analysis), an online tool that can evaluate the validity of the 3D structure of the protein was used. It generates an outcome called z-score. In this this study, the z-score of MtKasA (PDB Code-2WGE) was calculated to be -9.45 .

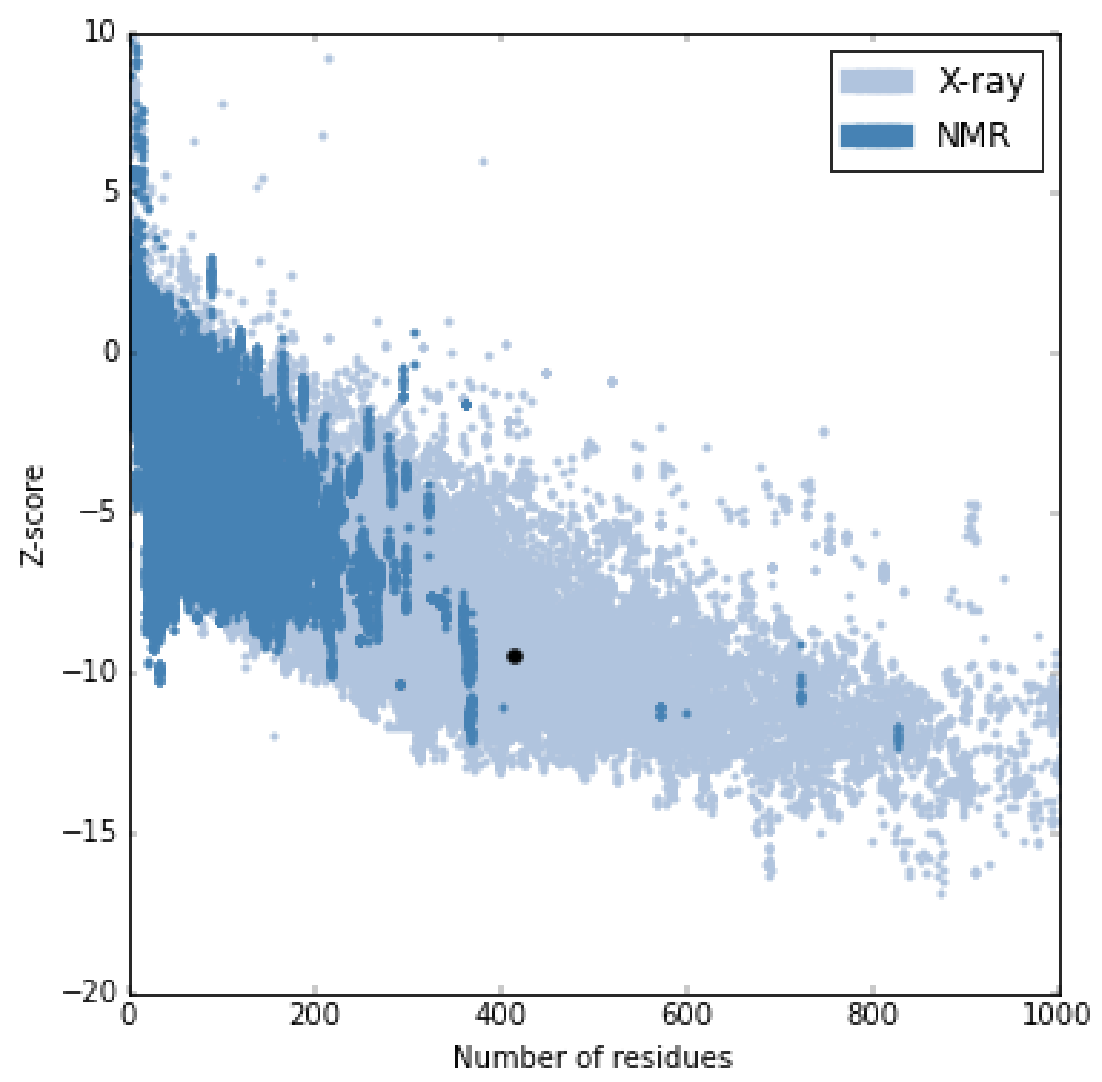

Figure 7 The z-score (-9.45) of MtKasA (PDB ID-2WGE) obtained from ProSA Web Server

In figure 7 , it is shown that the $\mathrm{z}$-score of MtKasA is in range with all the experimentally determined protein chains in current PDB. 


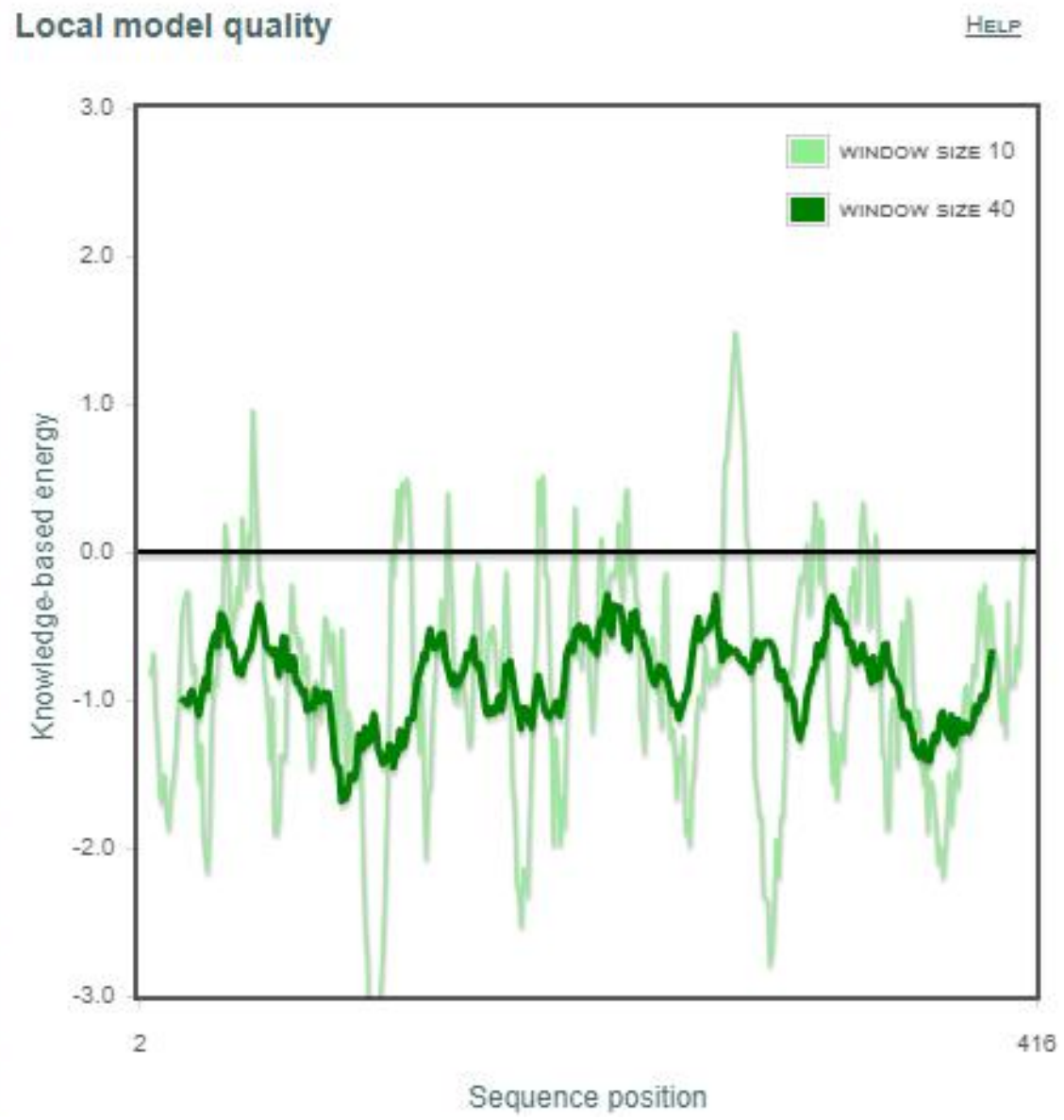

Figure 8:The local model quality of MtKasA

Also, in Figure 8 the local model quality of MtKasA can be seen to mostly below positive value which indicates that there is no error in the 3D structure of the protein (Wiederstein \& Sippl, 2007). Therefore, this structure is valid.

Secondly, the validation of 3D protein was also performed in PROSSESS. The overall quality factor 6.5 of the protein after running PROSSESS was found to be which is considered to be a good value (Berjanskii et al., 2010). 


\subsubsection{MtPanK 3D Structure validation}

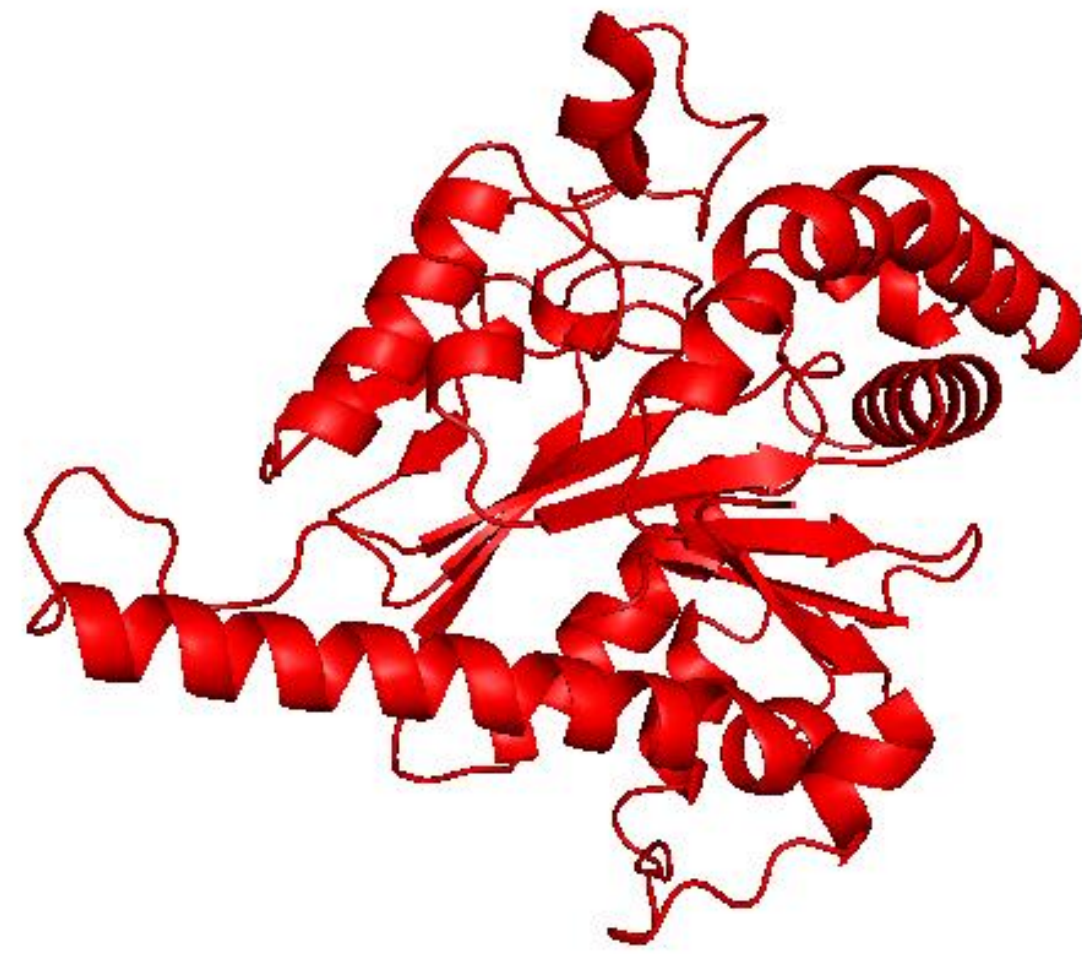

Figure 9: 3D structure of MtPank (PDB ID-4BFT) without heteroatoms obtained from PyMol

The above figure shows the 3D structure of MtPanK on a visualizing tool named PyMOL. The alpha helix and beta sheet of the protein MtPanK can be visualized in this tool. 


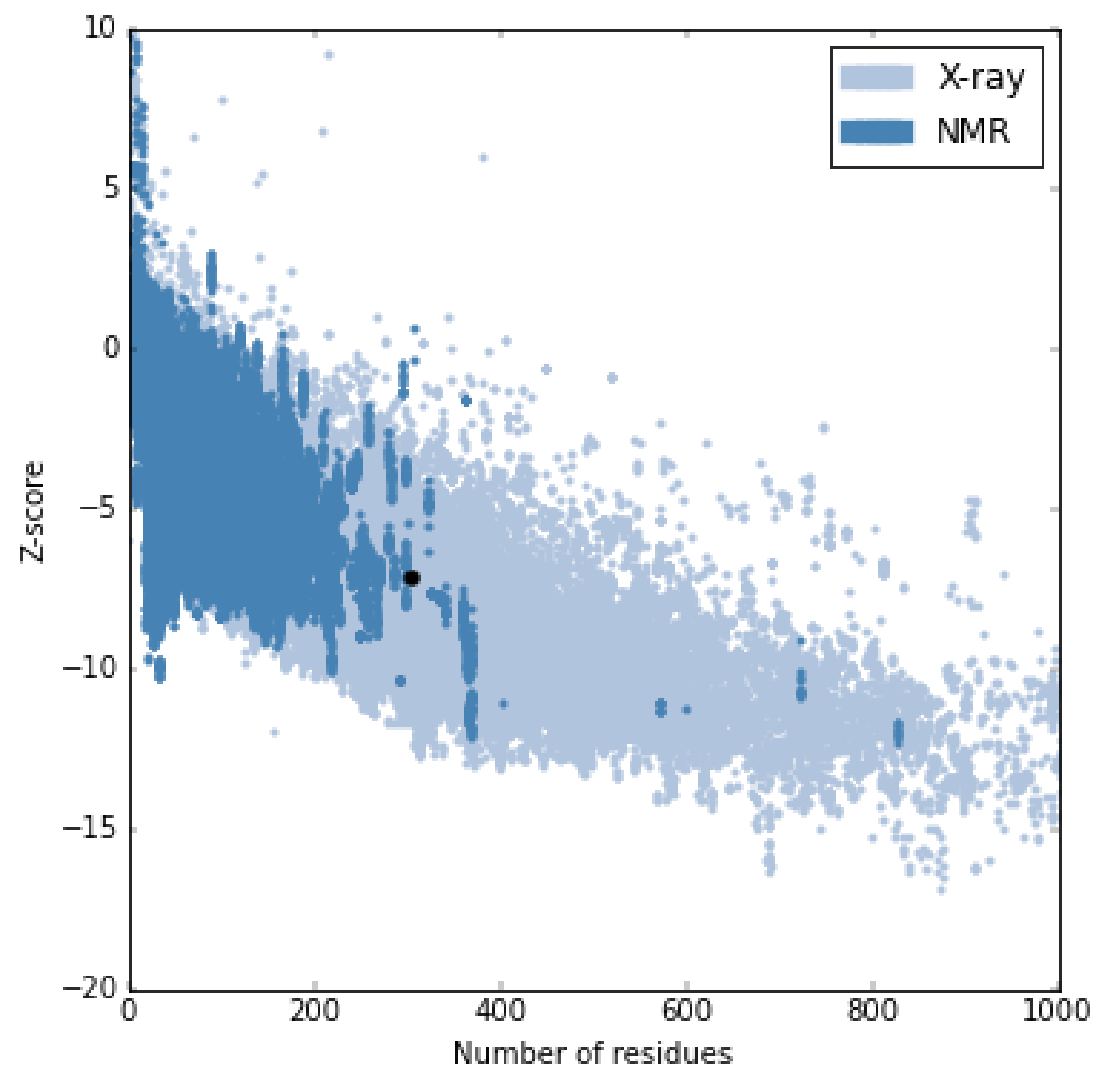

Figure 10: The z-score (-7.13) of MtPanK (PDB ID-4BFT) obtained from ProSA Web In order to determine the three-dimensional structure quality of the protein, ProSA (Protein Structure Analysis), an online tool that can evaluate the validity of the 3D structure of the protein was used. It generates an outcome called z-score. In this this study, the z-score of MtPanK (PDB Code-4BFT) was calculated to be -7.13 . 


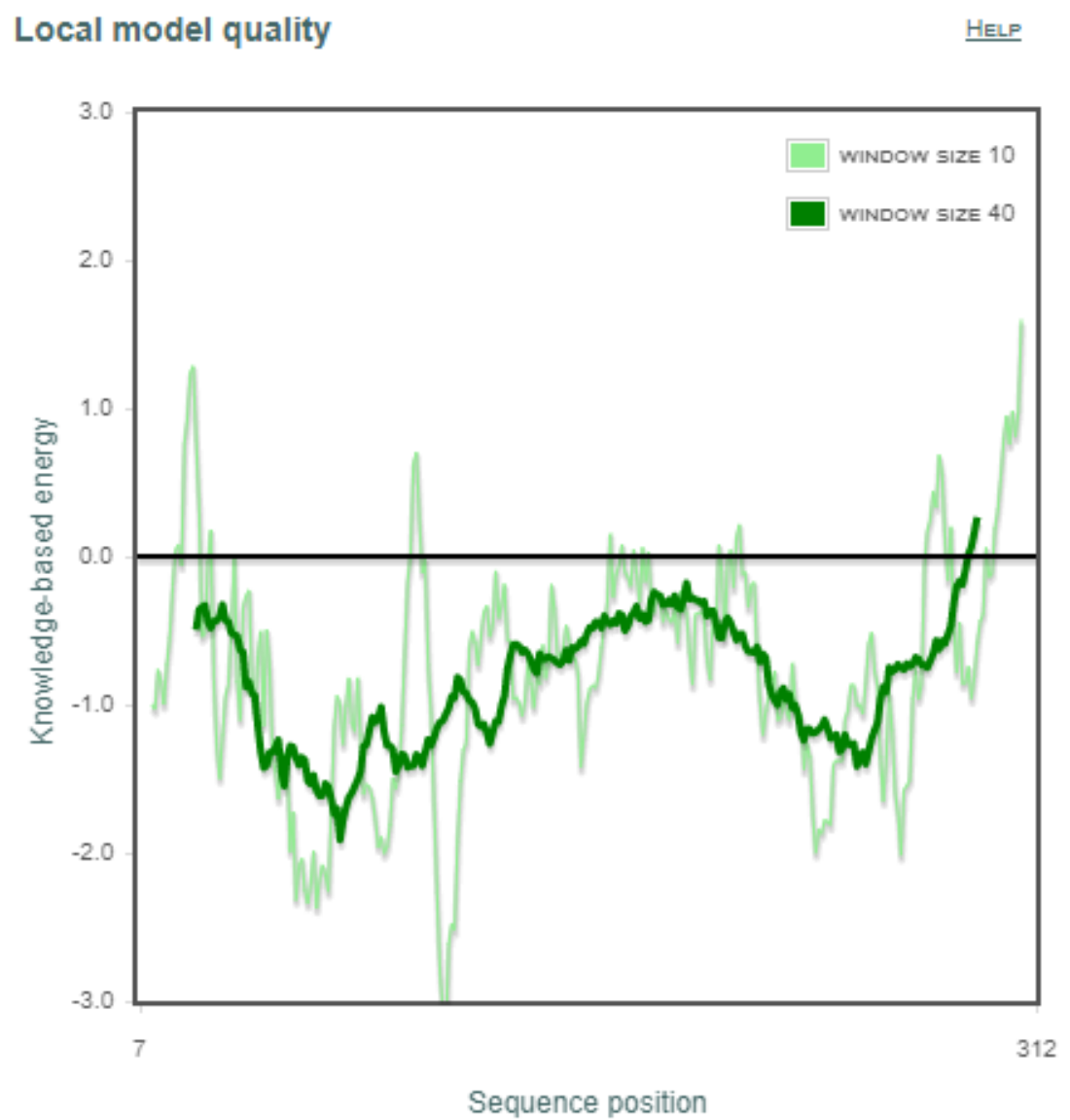

Figure 11: The local model quality of MtPanK

In figure 10, it is shown that the z-score of MtPanK is in range with all the experimentally determined protein chains in current PDB. Also, in figure 11 the local model quality of MtPanK can be seen to mostly below positive value which indicates that there is no error in the 3D structure of the protein (Wiederstein \& Sippl, 2007). Therefore, this structure is valid.

Secondly, the validation of 3D protein was also performed in PROSSESS. The overall quality of the protein after running PROSESS was found to be 4.5 which is considered to be an acceptable value (Berjanskii et al., 2010).

\subsubsection{MtPnkB 3D Structure validation}

The above figure shows the 3D structure of MtPnkB on a visualizing tool named PyMOL. The alpha helix and beta sheet of the protein MtPnKB can be visualized in this tool. 


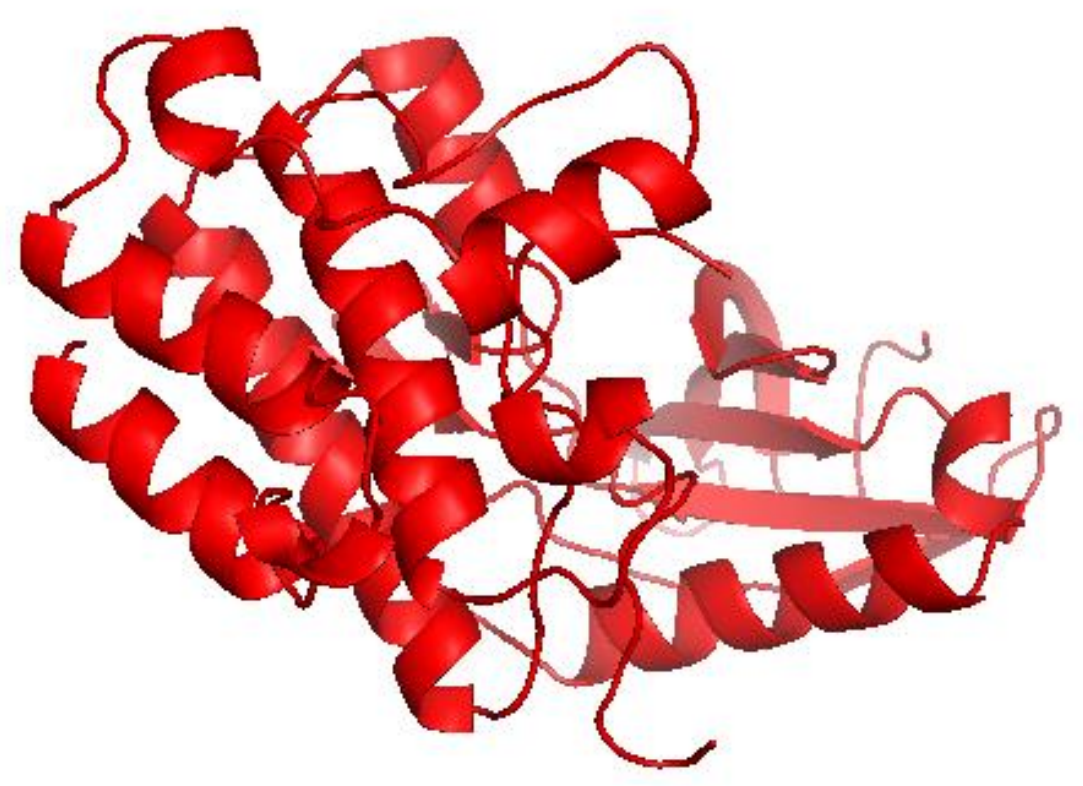

Figure 12:3D structure of MtPnkB (PDB ID-2FUM) without heteroatoms obtained from PyMol The figure showed the 3D structure of MtPknB.

In order to determine the three-dimensional structure quality of the protein, ProSA (Protein Structure Analysis), an online tool that can evaluate the validity of the 3D structure of the protein was used. It generates an outcome called z-score. In this this study, the z-score of MtPnkB (PDB Code-2FUM) was calculated to be -7.36 . 


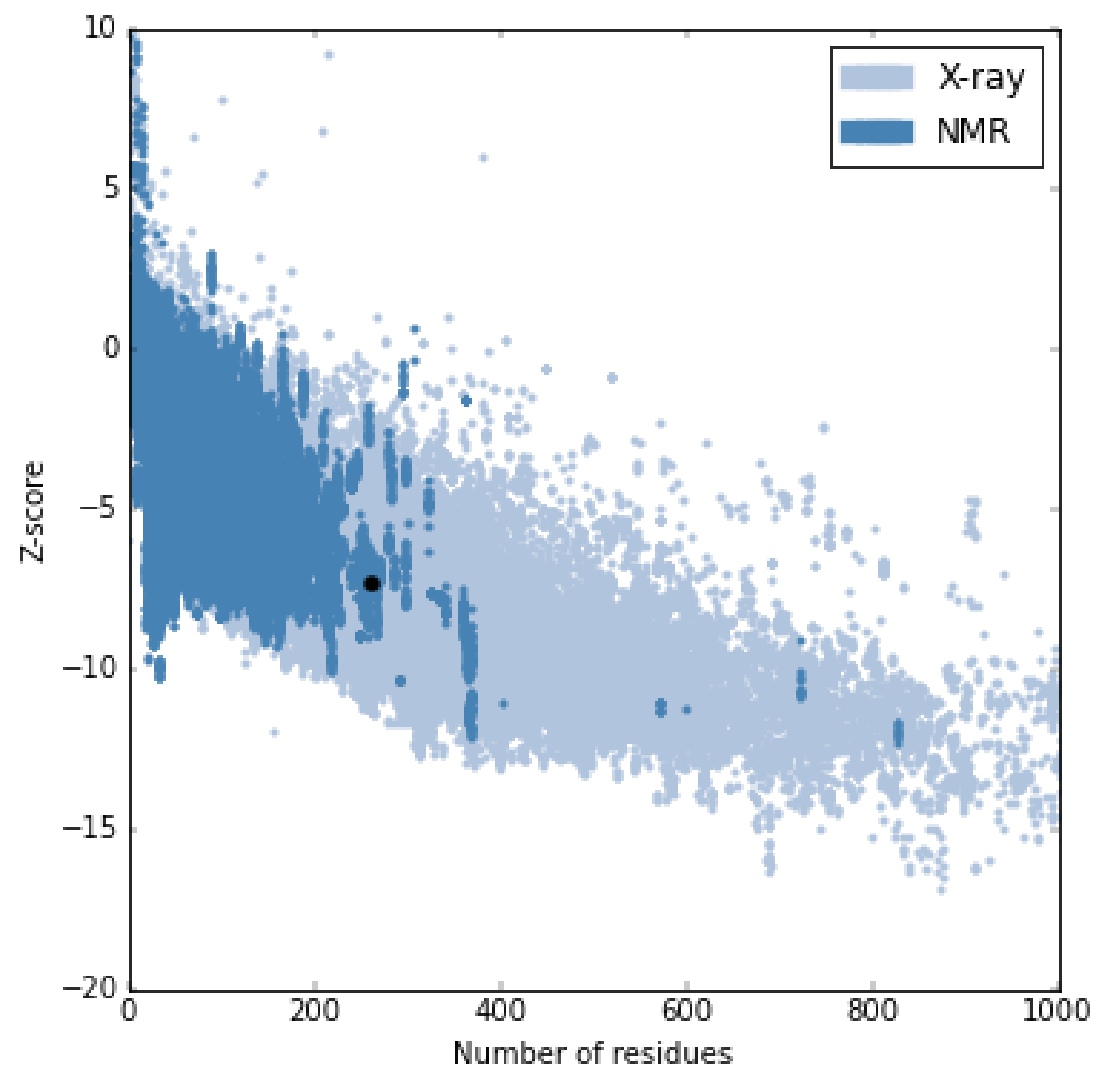

Figure 13: The z-score (-7.36) of MtKnB (PDB ID-4BFT) obtained from ProSA Web

In figure 13, it is shown that the z-score of MtPnkB is in range with all the experimentally determined protein chains in current PDB. 


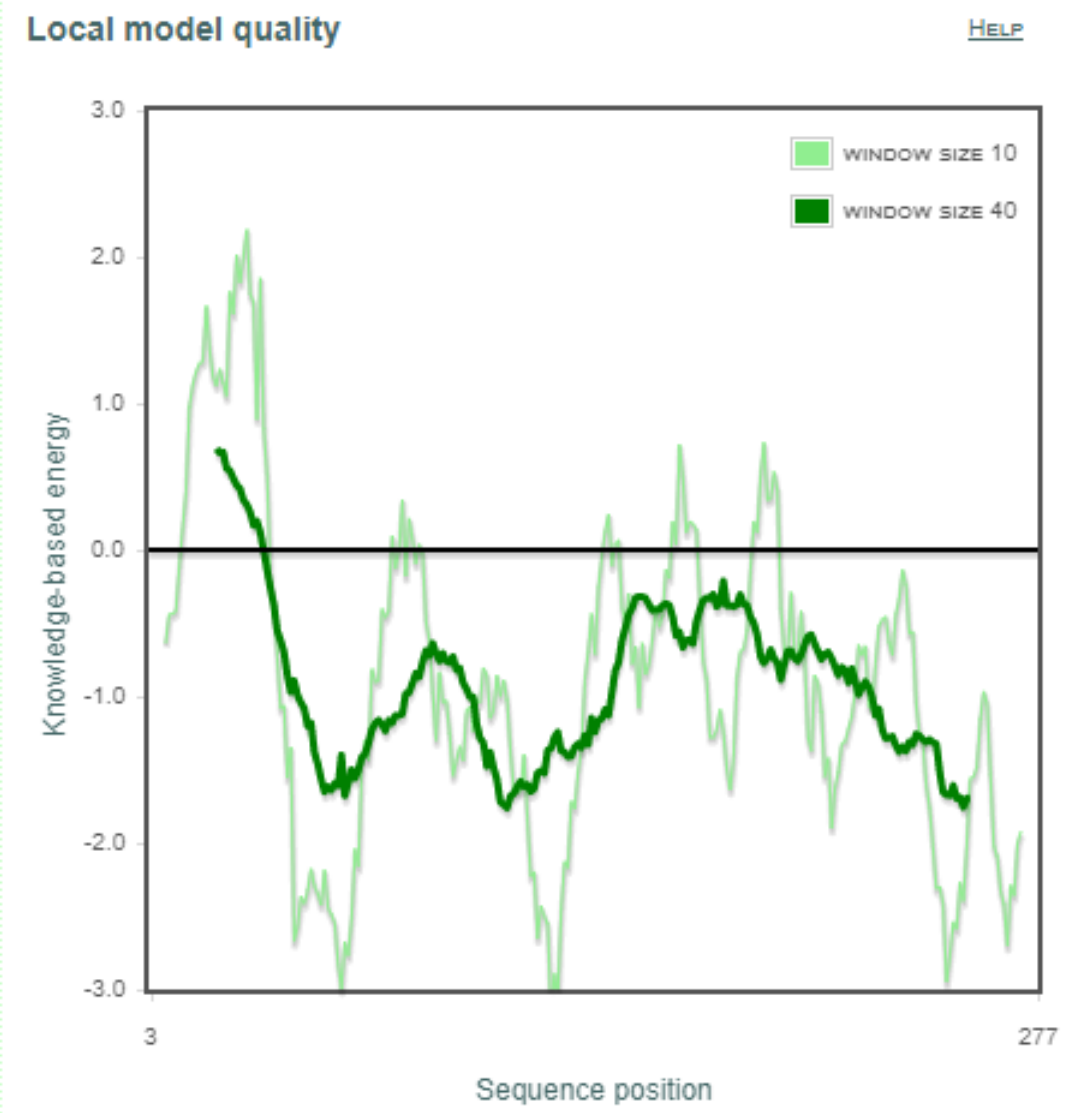

Figure 14: local model quality of MtPknB

Also, in figure 14 the local model quality of MtPnkB can be seen to mostly below positive value which indicates that there is no error in the 3D structure of the protein (Wiederstein \& Sippl, 2007). Therefore, this structure is valid.

Secondly, the validation of 3D protein was also performed in PROSSESS. The overall quality factor 6.5 of the protein after running PROSESS was found to be which is considered to be a good value(Berjanskii et al., 2010). 


\subsubsection{MtDprE1 3D Structure Validation}

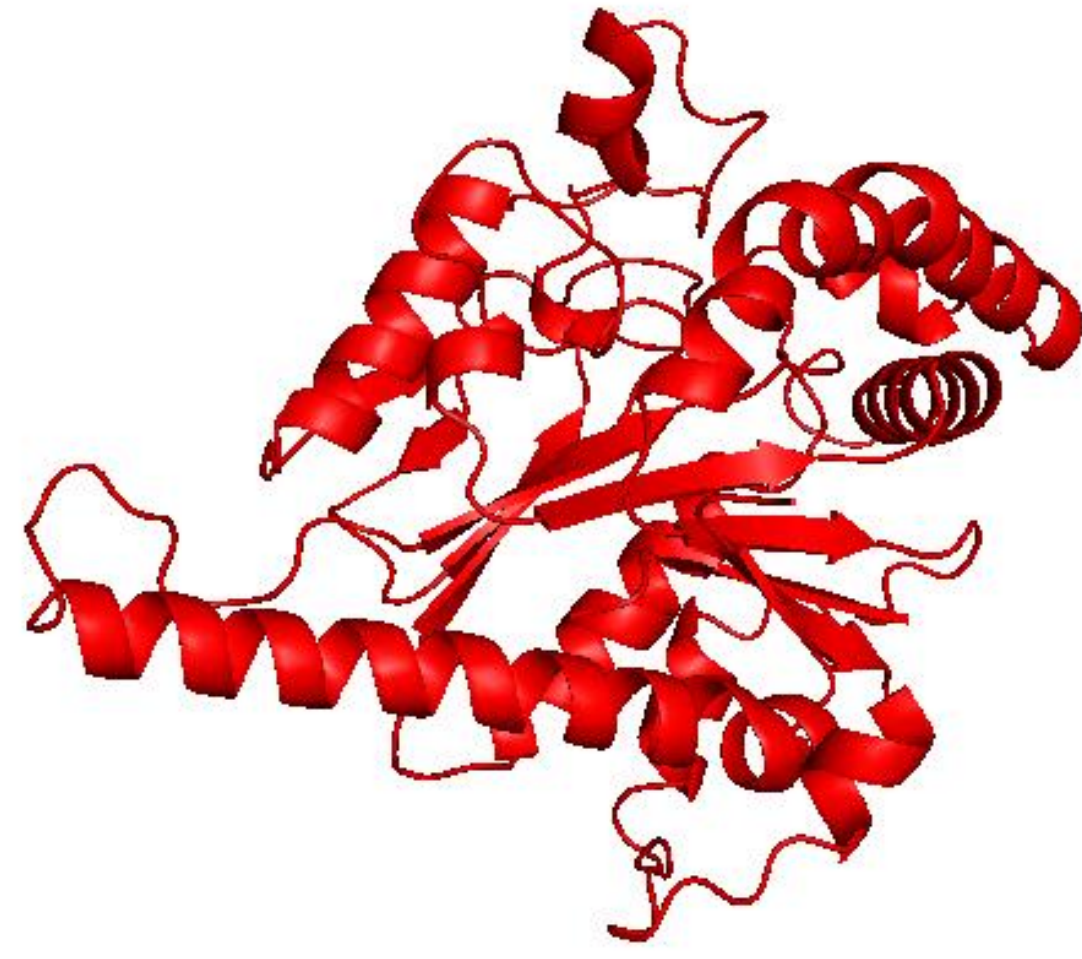

Figure 15: 3D structure of MtPnkB (PDB ID-4FF6) without heteroatoms obtained from PyMol

The above figure shows the 3D structure of MtDprE1 on a visualizing tool named PyMOL. The alpha helix and beta sheet of the protein MtDprE1 can be visualized in this tool.

In order to determine the three-dimensional structure quality of the protein, ProSA (Protein Structure Analysis), an online tool that can evaluate the validity of the 3D structure of the protein was used. It generates an outcome called z-score. In this this study, the z-score of MtDprE1 (PDB Code-4FF6) was calculated to be -9.91 . 


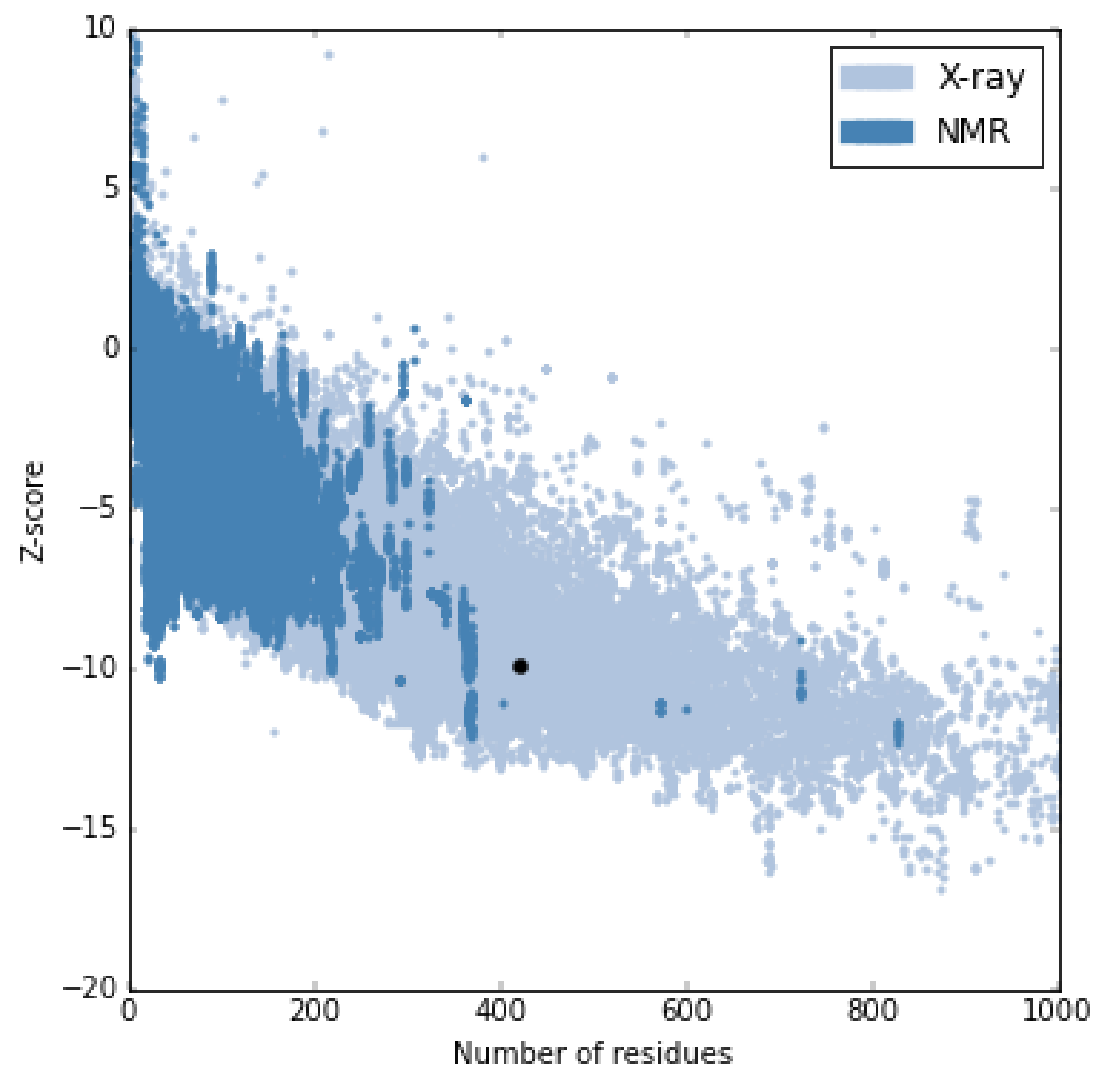

Figure 16: The z-score (-7.36) of MtDprE1 (PDB ID-4FF6) obtained from ProSA Web

In figure 16, it is shown that the z-score of MtDprE1 is in range with all the experimentally determined protein chains in current PDB.

Also, in figure 17 the local model quality of MtDprE1 can be seen to mostly below positive value which indicates that there is no error in the 3D structure of the protein (Wiederstein $\&$ Sippl, 2007). Therefore, this structure is valid. 


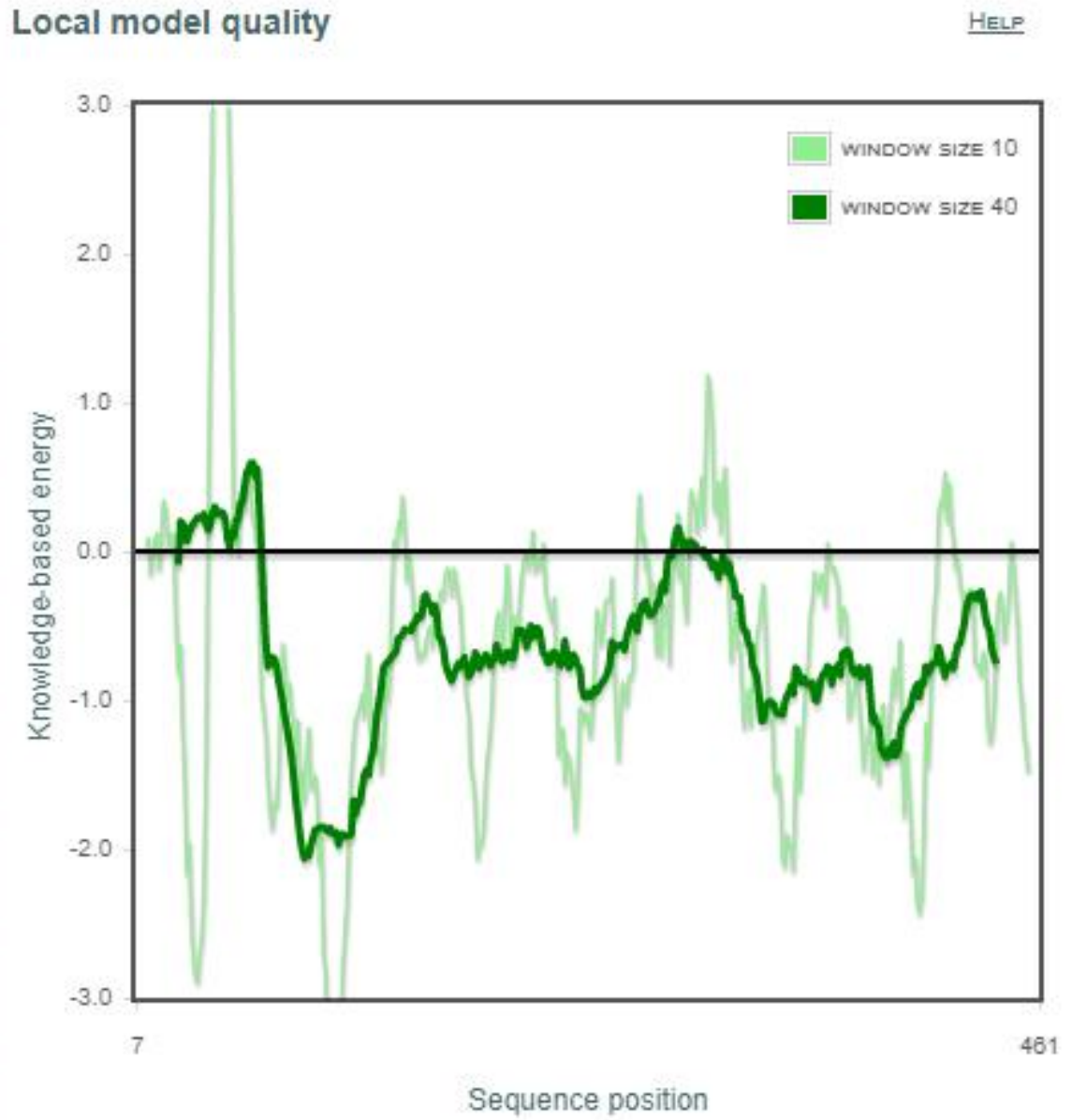

Figure 17:Local model quality MtDprE1

Secondly, the validation of 3D protein was also performed in PROSSESS. The overall quality factor of the protein after running PROSESS was found to be 6.5 which is considered to be a good value (Berjanskii et al., 2010).

\subsection{In silico binding results obtained after docking}

Torsions are activated but not fixed in flexible docking where in rigid docking, torsions are fixed and the movement of the molecules are not allowed. This makes the drug molecules less shaky while being docked with the receptor. For this study, AutoDock tools and AutoDock Vina were used and the results of rigid docking in terms of binding affinities are given below: 
Table 2: binding affinities of proteins with alkaloid compound (proposed ligand)

\begin{tabular}{|l|l|l|l|l|}
\hline Protein Name & Docking Score & Docking scores & Docking Scores & Docking scores \\
& for & for & for Decarine & for \\
& & B & & Monoamphilceti \\
& & Brachystamide & & A \\
\hline MtPanK (4BFT) & -10.7 & -8.6 & -9.6 & -7.5 \\
\hline MtDprE1 & -9.7 & -9.7 & -9.1 & -9.8 \\
\hline MtPknB & -9.0 & -9.1 & & \\
\hline$(2 F U M)$ & & & -9.7 & -7.2 \\
\hline MtKasA & -8.5 & -8.4 & -7.8 & \\
\hline$(2 W G E)$ & & & & \\
\hline
\end{tabular}

Table 2 contains all the value of binding affinities of different alkaloids (S. K. Mishra et al., 2017 )against four different proteins which are essential for the survival of Mycobacteria.

Table 3: Binding affinity towards proteins and standard

\begin{tabular}{|l|l|l|}
\hline Protein Name & Standard Name & Standard Docking Score \\
\hline MtPanK (4BFT) & ZVT & -7.3 \\
\hline MtDprE1 (4FF6) & 0T4 & -9.2 \\
\hline MtPknB (2FUM) & MIX & -10.8 \\
\hline MtKasA (2WGE) & TLM & -7.9 \\
\hline
\end{tabular}

Table 3. contains all the binding affinities between standard inhibitors and four proteins which are essential for the survival of mycobacteria. 


\subsection{Visualization and Validation}

Visualizing was done using PyMOL, then ligand-protein interactions were done using Discovery Studio.

\subsubsection{Visualization using PyMOL}

PyMOL validation mainly involved visualization of the protein structures in complex with the potential drugs and reference drugs as ligands. The 'pdbqt' files generated by using Autodock Vina and Autodock Tools docking method, were visualized after loading the protein structures (2WGE,2FUM,4BFT,4FF6). There were available nine sites in which ligands were bound and any of them can be used to validate with the reference. Only the protein-ligand complexes of different classes of drugs that superimposed with any of the protein-ligand complex of established standard drugs are given.

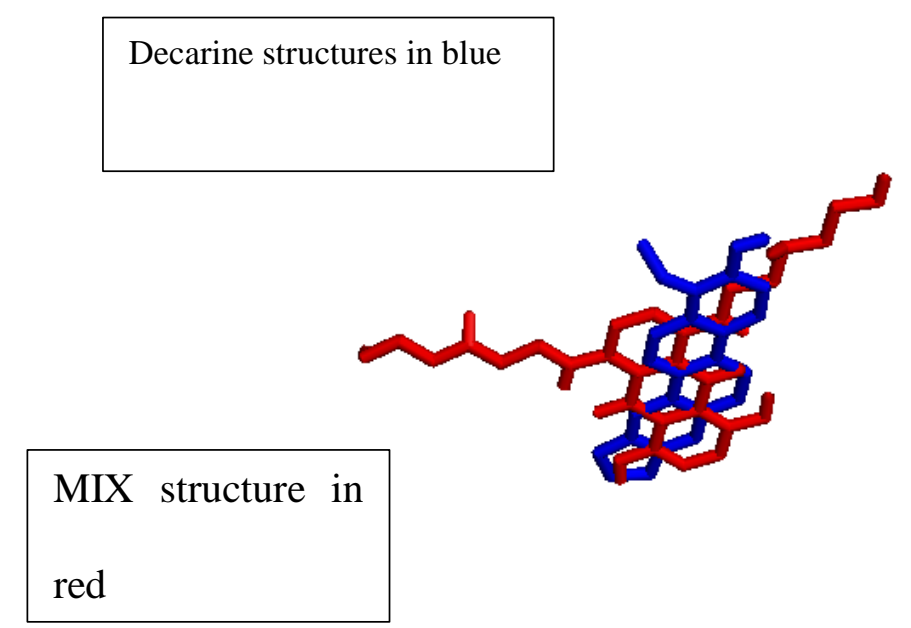

Figure 18: Superimposition of Decarine and MIX structures in the same binding pocket 
OT4 structure in red

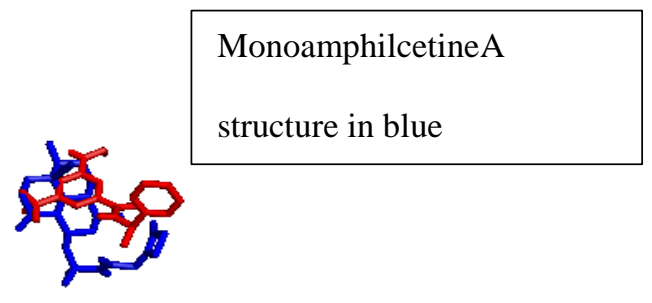

Figure 19: Superimposition of Monoamphilcetine and OT4

Bracystamide B structure is in blue

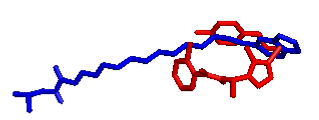

ZVT structure is in red

Figure 20:Bracystamide and ZVT bind to the same binding pocket 


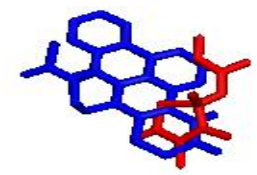

Shermilamine B structurein blue

Figure 21: Shermilamine B and TLM bind to the same binding pocket

Figure (18-21) shows the superimposition alkaloids with established inhibitors with the wellestablished standards in PyMOL. The superimposition result indicates that these drugs might bind to the same binding pockets as their respective standards.

\subsubsection{Validation by using Discovery Studio}

The distances between the amino acids of protein and ligands were also evaluated using Discovery Studio Visualizer (Dassault Systèmes BIOVIA, 2010) It was done by observing the involved amino acids, bonds formed between amino acids and ligands, type and category of the bonds and lastly distances between the bonds.

\section{Protein-ligand interaction of 4BFT-ZVT drug complex}

At first, the interactions of established standard ZVT with MtPanK was observed in Discovery Studio Visualizer. 


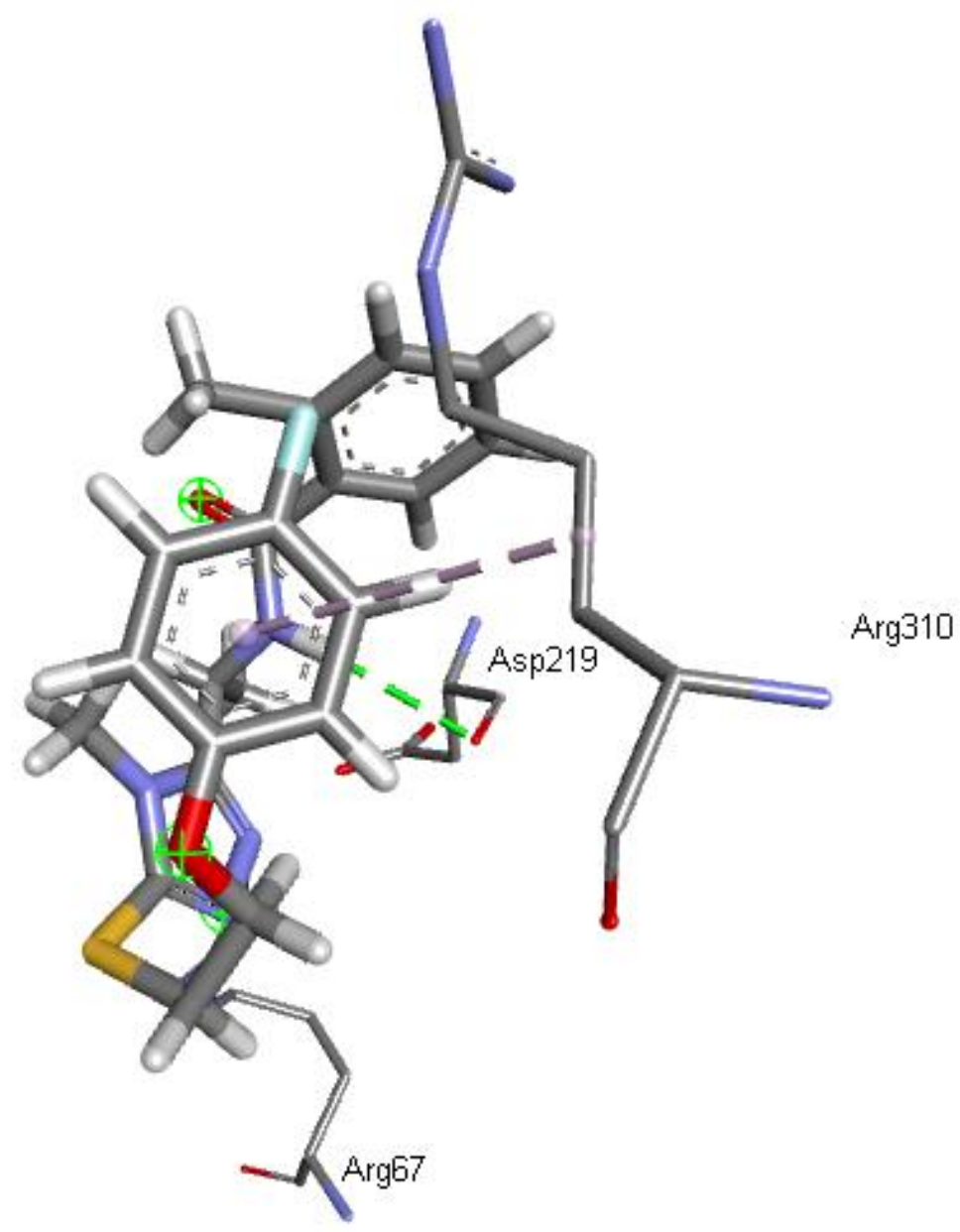

Figure 22: ZVT interaction with MtPanK (4BFT)

Figure 22 described the interactions between ZVT and MtPanK.

Table 4:ZVT interaction with MtPank (4BFT)

\begin{tabular}{|l|l|l|l|}
\hline \multicolumn{1}{|c|}{ Name } & \multicolumn{1}{|c|}{ Category } & Type & Distance \\
\hline A: ARG67:NH1 -: UNL1: N & Hydrogen Bond & Conventional Hydrogen Bond & 3.36209 \\
\hline : UNL1:H - A:ASP219:O & Hydrogen Bond & Conventional Hydrogen Bond & 2.78571 \\
\hline : UNL1 - A: ARG310 & Hydrophobic & Pi-Alkyl & 5.25027 \\
\hline
\end{tabular}

Table 4 shows that MtPank-ZVT complex formed 2 different bonds with three amino acids.

The amino acids were ARG66, ASP 219 and ARG310. Two of the bonds were hydrogen bond and one hydrophobic bond. The length of all the hydrophobic bonds ranged from 2.7 to 5.3 angstroms. As all the bonds formed here are hydrophobic and hydrogen bonds it represents a 
good ligand-protein interactions because these two bonds are fundamental players to form strong bond (Patil et al., 2010).

\section{Protein Ligand interaction of 4BFT-Brachystamide B Interaction}

The interactions of established brachystamide B with MtPanK was observed in Discovery Studio Visualizer.

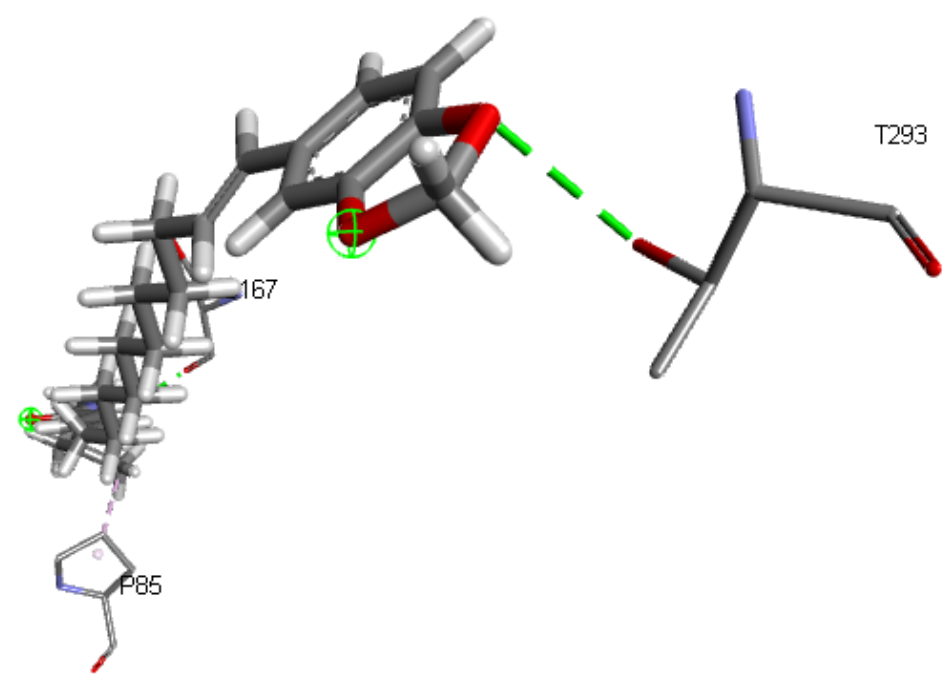

Figure 23: Brachystamide B interaction with MtPanK(4BFT)

Figure 23 describes the interaction between Brachystamide B and MtPanK.

Table 5: brachystamide B interaction with MtPanK(4BFT)

\begin{tabular}{|l|l|l|l|}
\hline Name & Category & Type & Distance \\
\hline A: THR293:OG1 -: UNL1:O & Hydrogen Bond & Conventional Hydrogen Bond & 3.00463 \\
\hline : UNL1:H - A: SER167:O & Hydrogen Bond & Conventional Hydrogen Bond & 2.01872 \\
\hline : UNL1:C - A:PRO85 & Hydrophobic & Alkyl & 3.91669 \\
\hline
\end{tabular}

Table 5 shows that MtPank-Bracystamide B complex formed 2 different bonds with three amino acids. The amino acids were THR293, SER 167 and PRO85. Two of the bonds were hydrogen bond and one hydrophobic bond. The length of all the hydrophobic bonds were ranged from 2.0 to 3.9 angstroms. As all the bonds formed here are hydrophobic and hydrogen 
bonds it represents a good ligand-protein interactions because these two bonds are fundamental players to form strong bond (Patil et al., 2010).There were no overlapping bonds in this case between the proposed and the standard drug but both strongly bind to the protein with same bond types. It is also known that hydrogen bonds are important in case of binding of a drug or ligand to a receptor (Davis \& Teague, 1997).

\section{Protein Ligand interaction of 4FF6-OT4 Interaction}

At first, the interactions of established standard OT4 with MtDprE1 was observed in Discovery Studio Visualizer.

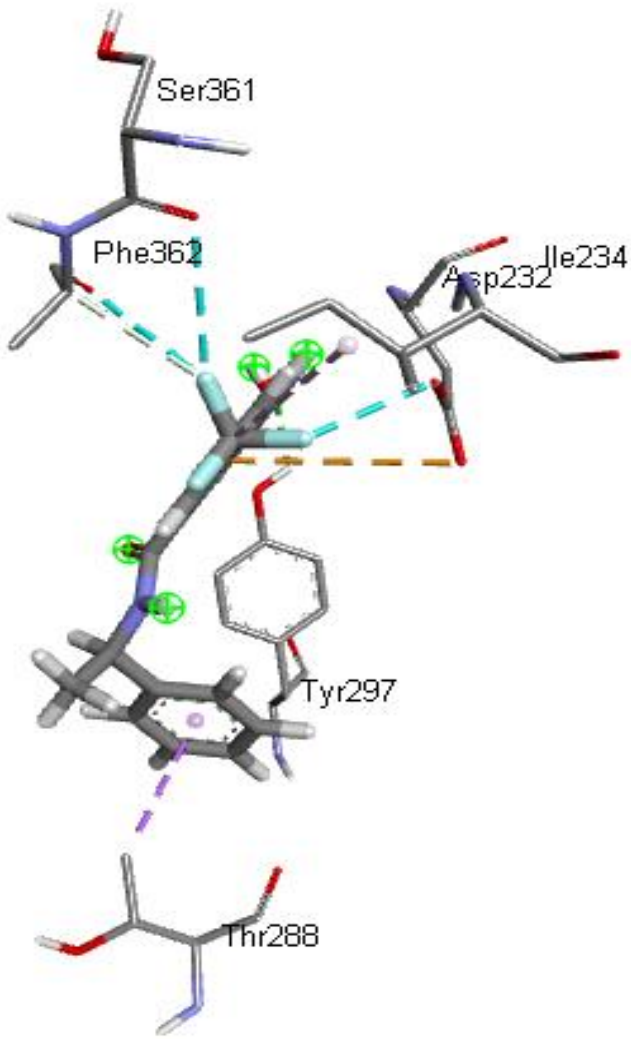

Figure 24:OT4 interaction with MtDprE1 (4FF6)

Figure 24 depicts the interaction of OT4 with MtDprE1.

Table 6: OT4 interaction with MtDprE1 (4FF6)

\begin{tabular}{|l|l|l|l|}
\hline Name & Category & Type & Distance \\
\hline
\end{tabular}




\begin{tabular}{|c|c|c|c|}
\hline $\begin{array}{l}\text { A: TYR297: HH -: } \\
\text { UNL1:O }\end{array}$ & Hydrogen Bond & Conventional Hydrogen Bond & 2.42752 \\
\hline $\begin{array}{l}\text { A: PHE362:CA } \quad-: \\
\text { UNL1: F }\end{array}$ & $\begin{array}{l}\text { Hydrogen Bond; } \\
\text { Halogen }\end{array}$ & $\begin{array}{l}\text { Carbon Hydrogen Bond; } \\
\text { Halogen (Fluorine) }\end{array}$ & 3.09613 \\
\hline $\begin{array}{l}\text { A: ASP232:OD1 -: } \\
\text { UNL1: F }\end{array}$ & Halogen & Halogen (Fluorine) & 2.77482 \\
\hline $\begin{array}{l}\text { A: SER361:O -: } \\
\text { UNL1: F }\end{array}$ & Halogen & Halogen (Fluorine) & 3.41764 \\
\hline $\begin{array}{l}\text { A: PHE362:O -: } \\
\text { UNL1: } F\end{array}$ & Halogen & Halogen (Fluorine) & 3.54048 \\
\hline $\begin{array}{l}\text { A: ASP232:OD2 -: } \\
\text { UNL1 }\end{array}$ & Electrostatic & Pi-Anion & 4.89466 \\
\hline $\begin{array}{l}\text { A: THR288:CG2 -: } \\
\text { UNL1 }\end{array}$ & Hydrophobic & Pi-Sigma & 3.88147 \\
\hline : UNL1:C - A: ILE234 & Hydrophobic & Alkyl & 4.71427 \\
\hline
\end{tabular}

Table 6 shows that MtDprE1-OT4 complex formed 4 different bonds with eight amino acids. The amino acids were TYR 297, PHE 362, ASP 232, SER 361, PHE 362, ASP 232, THR 288 and ILE234. The bond types were one hydrogen bond, four halogen bond, one electrostatic bond and two hydrophobic bonds were seen. The distance range was 2.4 to 4.89 Armstrong. The hydrogen bonds are important for biological function and halogen bonds not only play a role in biological functions but also increases membrane permeability (Zaldini Hernandes, Melo Cavalcanti, Rodrigo Moreira, Filgueira de Azevedo Junior, \& Cristina Lima Leite, 2010).

\section{Protein Ligand interaction of 4FF6-Monoamphilectine A Interaction}

Then interactions between MtDprE1 and monoamphilectine A was observed. 


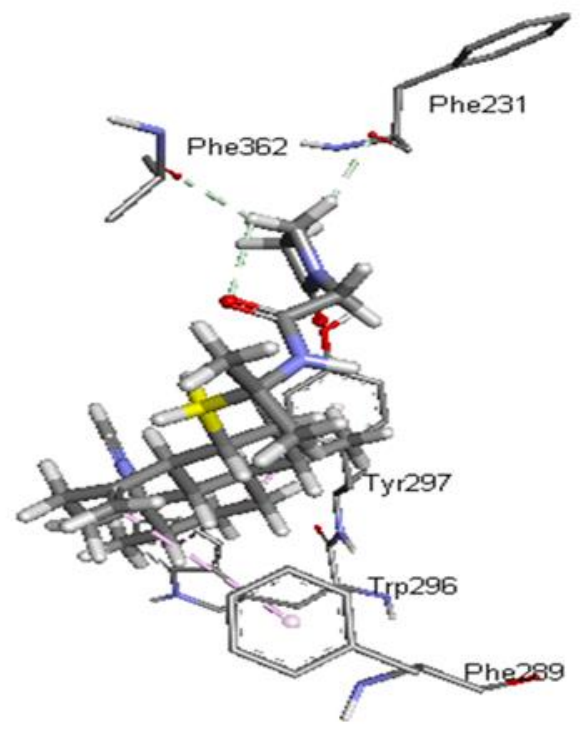

Figure 25: Monoamphilectine A interaction with MtDprE1 (4FF6)

Figure 25 depicts the interaction of Monoamphilectine A with MtDprE1.

Table 7: Monoamphilectine A interaction with MtDprE1 (4FF6)

\begin{tabular}{|c|c|c|c|}
\hline Name & Category & Type & Distance \\
\hline $\begin{array}{l}\text { UNL1:H36 - A: } \\
\text { PHE231:O }\end{array}$ & Hydrogen Bond & $\begin{array}{l}\text { Carbon Hydrogen } \\
\text { Bond }\end{array}$ & 2.20582 \\
\hline $\begin{array}{l}\text { : UNL1:H37 - A: } \\
\text { PHE362:O }\end{array}$ & $\begin{array}{l}\text { Hydrogen } \\
\text { Bond }\end{array}$ & $\begin{array}{l}\text { Carbon Hydrogen } \\
\text { Bond }\end{array}$ & 2.31394 \\
\hline : UNL1:H37 -: UNL1:O & Hydrogen Bond & $\begin{array}{l}\text { Carbon Hydrogen } \\
\text { Bond }\end{array}$ & 2.93292 \\
\hline A: PHE289 -: UNL1:C & Hydrophobic & Pi-Alkyl & 4.79301 \\
\hline A: TRP296 -: UNL1 & Hydrophobic & Pi-Alkyl & 5.37054 \\
\hline A: TRP296 -: UNL1:C & Hydrophobic & Pi-Alkyl & 4.32284 \\
\hline A: TYR297 -: UNL1 & Hydrophobic & Pi-Alkyl & 4.69661 \\
\hline A: TYR297 -: UNL1:C & Hydrophobic & Pi-Alkyl & 4.02288 \\
\hline
\end{tabular}

Protein Ligand interaction of 2WGE-TLM Interaction 
At first interaction between MtKasA and TLM was observed.

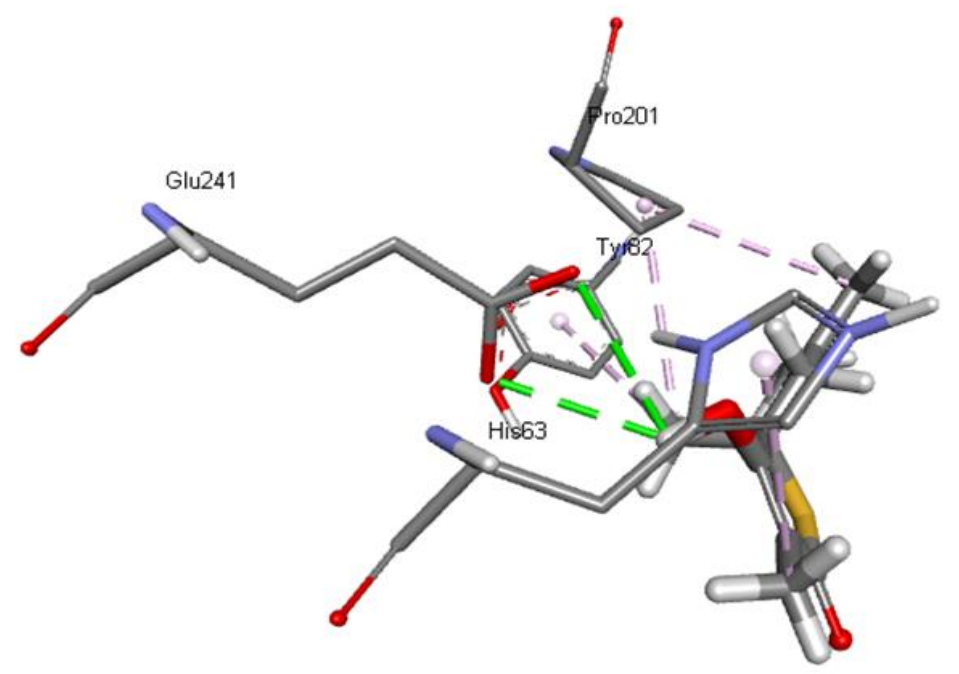

Figure 26: MtKasA (2WGE) interaction with TLM

Figure 26 depicts the relationship between MtKasA and TLM.

Table 8 MtKasA (2WGE) interaction with TLM

\begin{tabular}{|c|c|c|c|}
\hline Name & Category & type & distance \\
\hline $\begin{array}{l}\text { : UNL1:H16 - A: } \\
\text { GLU241:OE1 }\end{array}$ & Hydrogen Bond & $\begin{array}{l}\text { Conventional } \\
\text { Hydrogen Bond }\end{array}$ & 2.79986 \\
\hline $\begin{array}{l}\text { : UNL1:H16 - A: } \\
\text { GLU241:OE2 }\end{array}$ & Hydrogen Bond & $\begin{array}{l}\text { Conventional } \\
\text { Hydrogen Bond }\end{array}$ & 2.93651 \\
\hline $\begin{array}{l}\text { UNL1:C } \\
\text { A:PRO201 }\end{array}$ & Hydrophobic & Alkyl & 4.28569 \\
\hline $\begin{array}{l}\text { UNL1:C } \\
\text { A:PRO201 }\end{array}$ & Hydrophobic & Alkyl & 4.283 \\
\hline A: HIS63 -: UNL1:C & Hydrophobic & Pi-Alkyl & 4.35015 \\
\hline A: TYR82 -: UNL1:C & Hydrophobic & Pi-Alkyl & 4.81105 \\
\hline
\end{tabular}




\section{Protein Ligand interaction of 2WGE-Shermilamine B Interaction}

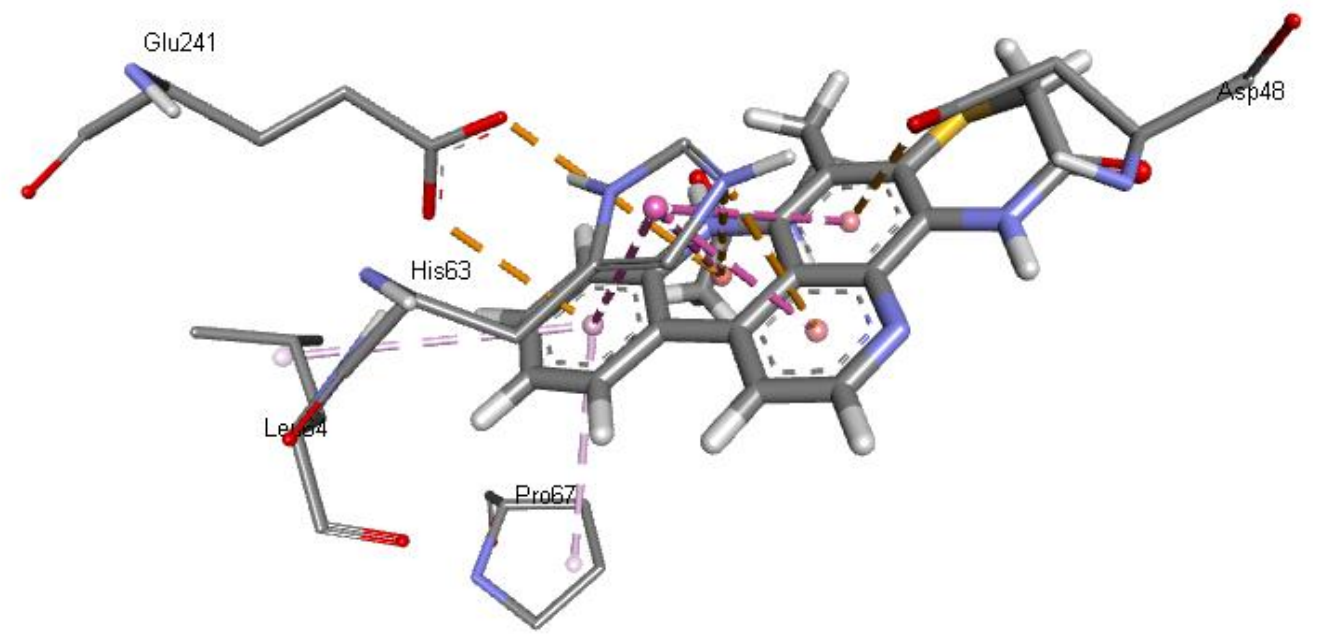

Figure 27: MtKasA (2WGE) interaction with shermilamine B

Figure 27 depicts the relationship between MtKasA and shermilamine B.

Table 9 MtKasA(2WGE) interaction with shermialmine $B$

\begin{tabular}{|ll|l|l|l|}
\hline Name & & Category & type & distance \\
\hline ANL1 HIS63:NE2 -: & Electrostatic & Pi-Cation & 4.98707 \\
\hline A: HIS63:NE2 -: & Electrostatic & Pi-Cation & 4.12141 \\
UNL1 & & & & \\
\hline A: ASP48:OD1 -: & Electrostatic & Pi-Anion & 3.59465 \\
UNL1 & & & 3.50896 \\
\hline A: GLU241:OE1 -: & Electrostatic & Pi-Anion & \\
UNL1 & & & \\
\hline
\end{tabular}




\begin{tabular}{|l|l|l|l|}
\hline A: GLU241:OE2 -: & Electrostatic & Pi-Anion & 4.76763 \\
\hline A: HIS63 -: UNL1 & Hydrophobic & Pi-Pi Stacked & 5.17818 \\
\hline A: HIS63 -: UNL1 & Hydrophobic & Pi-Pi Stacked & 4.51222 \\
\hline A: HIS63 -: UNL1 & Hydrophobic & Pi-Pi Stacked & 4.07021 \\
\hline A: HIS63 -: UNL1 & Hydrophobic & Pi-Pi Stacked & 5.14851 \\
\hline : UNL1 - A: LEU64 & Hydrophobic & Pi-Alkyl & 5.31768 \\
\hline : UNL1 - A:PRO67 & Hydrophobic & Pi-Alkyl & 4.70543 \\
\hline
\end{tabular}

\section{Protein Ligand interaction OF 2FUM-MIX Interaction}

At first interaction between MtPnkB and MIX was observed.

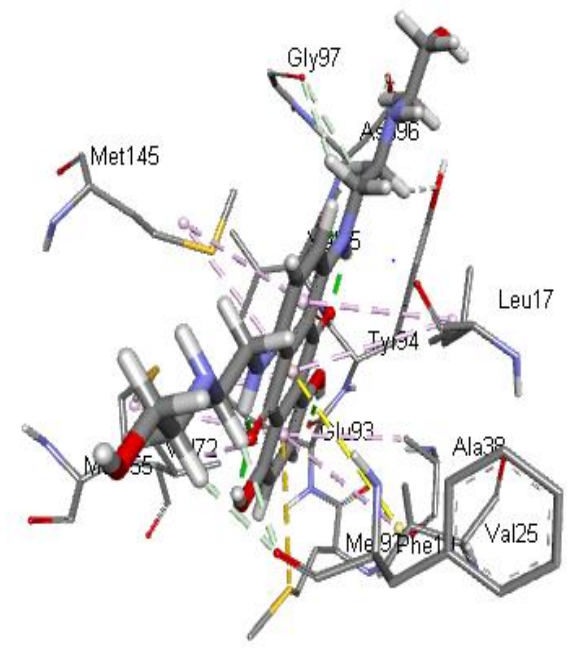

Figure 28:MtPknB interaction with MIX

Figure 28 depicts the relationship between MIX and MtPknB.

Table 10: MtPnkB interaction with MIX

\begin{tabular}{|l|l|l|l|}
\hline Name & Category & Type & Distance \\
\hline
\end{tabular}




\begin{tabular}{|c|c|c|c|}
\hline : UNL1:H -: UNL1:O & Hydrogen Bond & $\begin{array}{l}\text { Conventional } \\
\text { Hydrogen Bond }\end{array}$ & 1.84355 \\
\hline $\begin{array}{l}\text { : UNL1:H }- \text { A: } \\
\text { VAL95:O }\end{array}$ & Hydrogen Bond & $\begin{array}{l}\text { Conventional } \\
\text { Hydrogen Bond }\end{array}$ & 2.93476 \\
\hline : UNL1:H -: UNL1:O & Hydrogen Bond & $\begin{array}{l}\text { Conventional } \\
\text { Hydrogen Bond }\end{array}$ & 1.84377 \\
\hline : UNL1:H -: UNL1:O & Hydrogen Bond & $\begin{array}{l}\text { Conventional } \\
\text { Hydrogen Bond }\end{array}$ & 1.73383 \\
\hline $\begin{array}{l}\text { : UNL1:H } \quad-\text { A: } \\
\text { GLU93:O }\end{array}$ & Hydrogen Bond & \begin{tabular}{|l|} 
Conventional \\
Hydrogen Bond
\end{tabular} & 2.24594 \\
\hline $\begin{array}{l}\text { : UNL1:H16 - A: } \\
\text { GLY97:O }\end{array}$ & Hydrogen Bond & $\begin{array}{l}\text { Carbon Hydrogen } \\
\text { Bond }\end{array}$ & 2.85809 \\
\hline $\begin{array}{l}\text { UNL1:H21 - A: } \\
\text { PHE19:O }\end{array}$ & Hydrogen Bond & $\begin{array}{l}\text { Carbon Hydrogen } \\
\text { Bond }\end{array}$ & 2.68451 \\
\hline $\begin{array}{l}\text { : UNL1:H23 - A: } \\
\text { VAL95:O }\end{array}$ & Hydrogen Bond & $\begin{array}{l}\text { Carbon Hydrogen } \\
\text { Bond }\end{array}$ & 2.48186 \\
\hline $\begin{array}{l}\text { : UNL1:H23 - A: } \\
\text { GLY97:O }\end{array}$ & Hydrogen Bond & $\begin{array}{l}\text { Carbon Hydrogen } \\
\text { Bond }\end{array}$ & 2.95277 \\
\hline $\begin{array}{l}\text { UNL1:H24 - A: } \\
\text { TYR94: OH }\end{array}$ & Hydrogen Bond & $\begin{array}{l}\text { Carbon Hydrogen } \\
\text { Bond }\end{array}$ & 3.04587 \\
\hline $\begin{array}{l}: \text { UNL1:H26 - A: } \\
\text { PHE19:O }\end{array}$ & Hydrogen Bond & $\begin{array}{l}\text { Carbon Hydrogen } \\
\text { Bond }\end{array}$ & 2.56435 \\
\hline $\begin{array}{l}\text { UNL1:H28 - A: } \\
\text { ASP96:OD2 }\end{array}$ & Hydrogen Bond & $\begin{array}{l}\text { Carbon Hydrogen } \\
\text { Bond }\end{array}$ & 2.66263 \\
\hline
\end{tabular}




\begin{tabular}{|c|c|c|c|}
\hline $\begin{array}{l}\text { A: MET92:SD -: } \\
\text { UNL1 }\end{array}$ & Other & Pi-Sulfur & 4.73507 \\
\hline : UNL1 - A: LEU17 & Hydrophobic & Pi-Alkyl & 4.90902 \\
\hline $\begin{array}{l}: \quad \text { UNL1 } \quad-\text { A: } \\
\text { MET145 }\end{array}$ & Hydrophobic & Pi-Alkyl & 5.1904 \\
\hline : UNL1 - A: VAL25 & Hydrophobic & Pi-Alkyl & 5.15215 \\
\hline : UNL1 - A: ALA38 & Hydrophobic & Pi-Alkyl & 4.5132 \\
\hline : UNL1 - A: VAL72 & Hydrophobic & Pi-Alkyl & 4.85314 \\
\hline $\begin{array}{l}: \text { UNL1 } \quad-\quad \text { A: } \\
\text { MET155 }\end{array}$ & Hydrophobic & Pi-Alkyl & 4.72422 \\
\hline : UNL1 - A: LEU17 & Hydrophobic & Pi-Alkyl & 5.06475 \\
\hline : UNL1 - A: VAL25 & Hydrophobic & Pi-Alkyl & 5.19899 \\
\hline : UNL1 - A: MET145 & Hydrophobic & Pi-Alkyl & 5.32043 \\
\hline $\begin{array}{l}\text { : UNL1 } \quad-\quad \text { A: } \\
\text { MET155 }\end{array}$ & Hydrophobic & Pi-Alkyl & 4.79271 \\
\hline : UNL1:H -: UNL1:O & Hydrogen Bond & $\begin{array}{l}\text { Conventional } \\
\text { Hydrogen Bond }\end{array}$ & 1.84355 \\
\hline
\end{tabular}

In table 10 it shows that, MtPnkB-MIX complex formed two different bonds with twenty-four amino acids. The bond types were all hydrogen and hydrophobic bonds. All hydrogen bonds are important for biological activity and the pi cation bonds plays an important role in molecular recognition and chemical and biological catalysis. (Dougherty, 2013) The distance range was 2.5 to 5.2 Armstrong.

\section{Protein Ligand interaction OF 2FUM and decarine Interaction}

Then interaction between MtPknB and decarine was observed. 


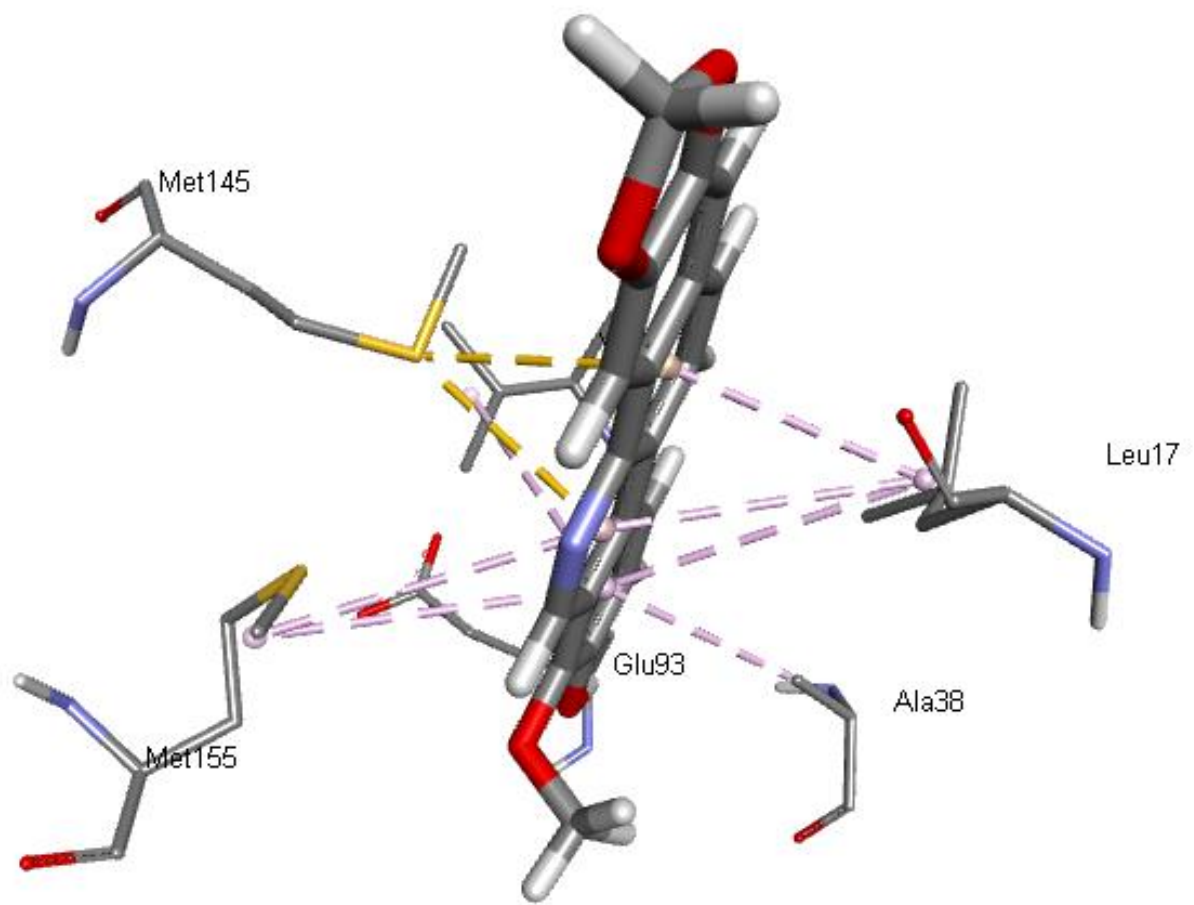

Figure 29:MtPknB interaction with decarine

Figure 29 depicts the relationship between MtPknB with decarine.

Table 11:MtPknB interaction with decarine

\begin{tabular}{|l|l|l|l|}
\hline Name & Category & Type & Distance \\
\hline GLU93:O & & Conventional & 2.10035 \\
\hline A: MET145:SD -: & Other & Pydrogen Bond & \\
UNL1 & & & 3.95549 \\
\hline A: MET145:SD -: & Other & Pi-Sulfur & \\
UNL1 & & & 4.08638 \\
\hline : UNL1 - A: & Hydrophobic & Pi-Alkyl & \\
\hline LEU17 & & & 4.83045 \\
\hline : UNL1 - A: LEU17 & Hydrophobic & Pi-Alkyl & \\
\hline
\end{tabular}




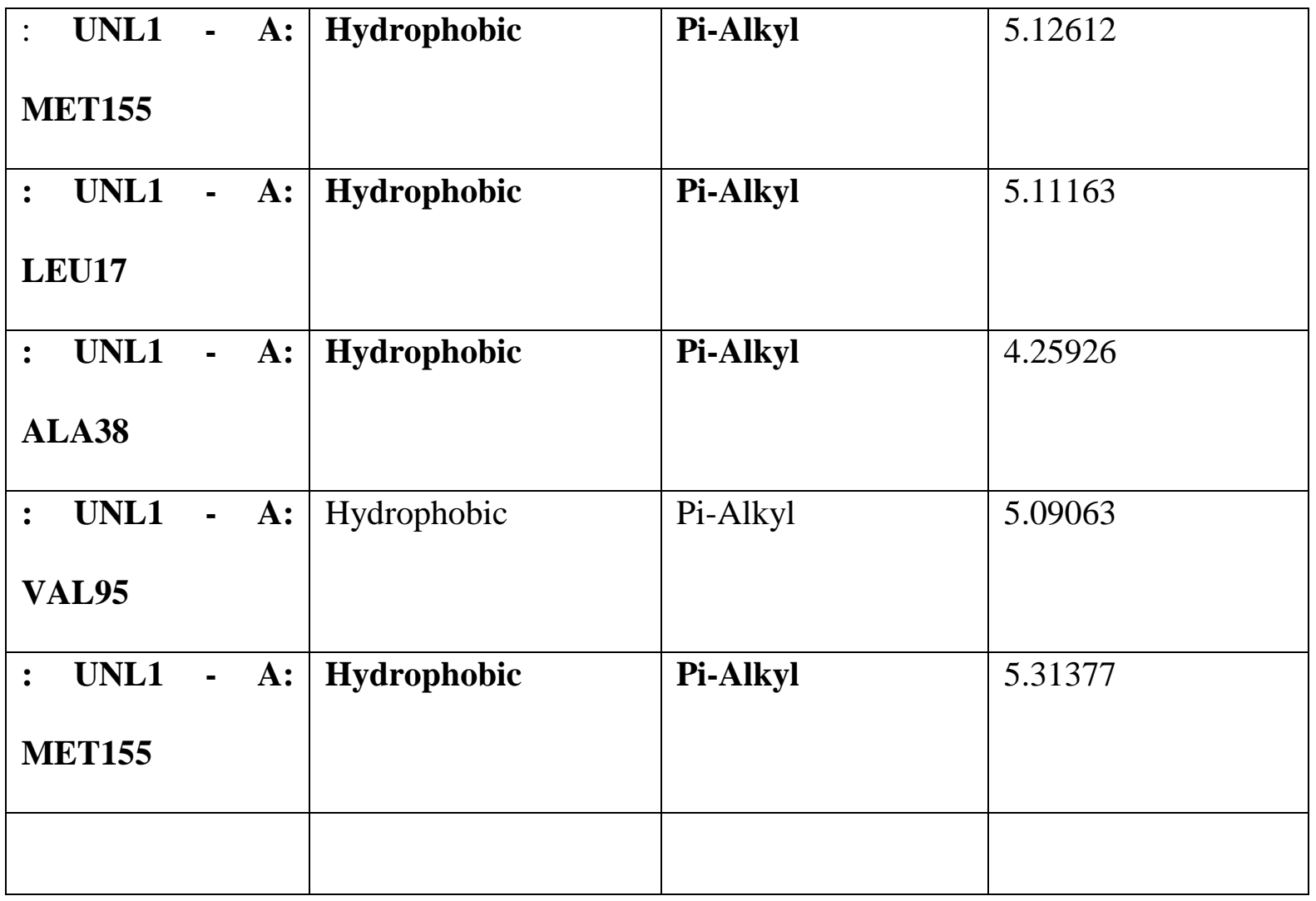

In table 11, MtPknB-decarine complex, formed bonds with 10 amino acids via three different bond types. The amino acids were GLU 93, MET145, MET 145, LEU17, MET 155, LEU17, ALA38, VAL95, MET 155.The bond types were hydrogen, hydrophobic or categorized as other. The observed distance range was 2.1 to 5.3 Armstrong.

By comparing it can be seen that, eight of the residues are same. GLU 93, LEU17, MET155, LEU17, ALA 38, MET 155 shared the same category of the bond which was hydrogen or hydrophobic bond. Hydrogen and hydrophobic bonds have importance in protein ligand interactions (Patil et al., 2010). The rest of the residues had shown to have different categories of bond type but all of them were strong bonds.

\subsection{Valditation through Ramachandran plot}

All the proteins and protein-drug complexes were evaluated in Ramachandran plot.("RAMPAGE: Ramachandran Plot Assessment," n.d.) The results obtained before and 
after the binding complex for favorable region and allowed region remained same before and after the binding with drug complex. As there were no variations in the residues and values were expected in can be said that the ligand-protein complexes are validated.

The table is given below:

\begin{tabular}{|l|l|l|}
\hline Protein name & $\begin{array}{l}\text { Value for allowed and } \\
\text { favored region before } \\
\text { complex formation }\end{array}$ & $\begin{array}{l}\text { Value for allowed and } \\
\text { favored region after complex } \\
\text { formation }\end{array}$ \\
\hline MtDprE1 & $98.4 \%(2.6 \%$ Outlier) & $98.4 \%(2.6 \%$ Outlier) \\
\hline MtKasA & $100 \%$ (no outlier) & $100 \%$ (no outlier) \\
\hline MtPanK & $99.7 \%(0.3 \%$ outlier) & $99.7 \%(0.3 \%$ outlier) \\
\hline MtPknB & $100 \%$ (no outlier) & $100 \%$ (no outlier) \\
\hline
\end{tabular}

\subsection{Drug choice}

The drug choice was done on the basis of the results of the validation stages.

\subsubsection{MtKasA (PDB ID:2WGE)}

The choice of drug to target the MtKasA protein is Shermilamine B. Shermilamine B showed a docking score of $-8.5 \mathrm{kcal} / \mathrm{mol}$ which was higher than the standard TLM score $(-7.9 \mathrm{kcal} / \mathrm{mol})$. Additionally, shermilamine B formed hydrophobic bonds and electro static bonds which have importance as a ligand, as previously discussed. Thus, shermilamine B is an ideal candidate for further studies.

Table 12: Physiochemical properties of standard and proposed drug

\begin{tabular}{|l|l|l|}
\hline The physiochemical & Property Value TLM & Property Value \\
properties of the proposed & & Shermilamine B \\
drug and the standard drug & & \\
\hline
\end{tabular}




\begin{tabular}{|c|c|c|}
\hline $\begin{array}{l}\text { obtained from PubChem } \\
\text { (Kim et al., 2016) are given } \\
\text { below for comparison : } \\
\text { Property Name }\end{array}$ & & \\
\hline Molecular Weight & $210.291 \mathrm{~g} / \mathrm{mol}$ & $390.461 \mathrm{~g} / \mathrm{mol}$ \\
\hline XLogP3-AA & 2.8 & 2.5 \\
\hline Hydrogen Bond Donor Count & 1 & 3 \\
\hline $\begin{array}{l}\text { Hydrogen Bond Acceptor } \\
\text { Count }\end{array}$ & 3 & 5 \\
\hline Rotatable Bond Count & 2 & 3 \\
\hline Exact Mass & $210.071 \mathrm{~g} / \mathrm{mol}$ & $390.115 \mathrm{~g} / \mathrm{mol}$ \\
\hline Monoisotopic Mass & $210.071 \mathrm{~g} / \mathrm{mol}$ & $390.115 \mathrm{~g} / \mathrm{mol}$ \\
\hline $\begin{array}{l}\text { Topological Polar Surface } \\
\text { Area }\end{array}$ & $62.6 \mathrm{~A}^{\wedge} 2$ & $108 \mathrm{~A}^{\wedge} 2$ \\
\hline Heavy Atom Count & 14 & 28 \\
\hline
\end{tabular}

The predicted ADMET properties (Absorption, Distribution, Metabolism, Excretion, Toxicity) properties are given below for the help of future lead optimization. ADMETSAR 2.0, an online tool, was used to do this (H. Yang et al., 2019). The green indicates that these values are in range for the parameter and the red indicates these values are out of the range for the parameter. 
Table 13:ADMET properties of the standard and proposed drug

\begin{tabular}{|c|c|c|c|c|}
\hline $\begin{array}{l}\text { ADMET } \\
\text { properties }\end{array}$ & $\begin{array}{l}\text { Value for } \\
\text { standard drug } \\
\text { TLM }\end{array}$ & $\begin{array}{l}\text { Probability for } \\
\text { standard drug } \\
\text { TLM }\end{array}$ & $\begin{array}{l}\text { Value for } \\
\text { Shermilamine B }\end{array}$ & $\begin{array}{l}\text { Probability of } \\
\text { Shermilamine B }\end{array}$ \\
\hline $\begin{array}{l}\text { Human } \\
\text { Intestinal } \\
\text { Absorption }\end{array}$ & + & 0.9876 & + & 0.8744 \\
\hline Caco-2 & + & 0.8584 & - & 0.8027 \\
\hline $\begin{array}{l}\text { Blood Brain } \\
\text { Barrier }\end{array}$ & + & 0.9656 & + & 0.9828 \\
\hline $\begin{array}{l}\text { Human oral } \\
\text { bioavailability }\end{array}$ & $\begin{array}{l}+ \\
\text { acceptable }\end{array}$ & $\begin{array}{l}0.5143 \\
\text { acceptable }\end{array}$ & Not acceptable & $\begin{array}{l}0.5000 \\
\text { Not acceptable }\end{array}$ \\
\hline $\begin{array}{l}\text { P-glycoprotein } \\
\text { inhibitor }\end{array}$ & - & 0.9696 & + & 0.6496 \\
\hline $\begin{array}{l}\text { Carcinogenicity } \\
\text { (binary) }\end{array}$ & $\begin{array}{l}- \\
\text { acceptable }\end{array}$ & $\begin{array}{l}0.6731 \\
\text { acceptable }\end{array}$ & $\begin{array}{l}- \\
\text { acceptable }\end{array}$ & $\begin{array}{l}0.8857 \\
\text { acceptable }\end{array}$ \\
\hline $\begin{array}{l}\text { Carcinogenicity } \\
\text { (trinary) }\end{array}$ & $\begin{array}{l}\text { Non-required } \\
\text { acceptable }\end{array}$ & $\begin{array}{l}0.5295 \\
\text { acceptable }\end{array}$ & $\begin{array}{l}\text { Non-required } \\
\text { acceptable }\end{array}$ & $\begin{array}{l}0.6517 \\
\text { acceptable }\end{array}$ \\
\hline $\begin{array}{l}\text { Ames } \\
\text { mutagenesis }\end{array}$ & $\begin{array}{l}- \\
\text { acceptable }\end{array}$ & $\begin{array}{l}0.7700 \\
\text { acceptable }\end{array}$ & $\begin{array}{l}+ \\
\text { Not acceptable }\end{array}$ & $\begin{array}{ll}0.6400 & \text { Not } \\
\text { acceptable } & \end{array}$ \\
\hline $\begin{array}{l}\text { Human either-a- } \\
\text { go-go inhibition }\end{array}$ & - & 0.8139 & + & 0.7932 \\
\hline $\begin{array}{l}\text { CYP inhibitory } \\
\text { promiscuity }\end{array}$ & - & 0.5616 & - & 0.6048 \\
\hline
\end{tabular}




\begin{tabular}{|l|l|l|l|l|}
\hline Acute Oral & III & 0.7235 & III & 0.6424 \\
Toxicity (c) & & & & \\
\hline
\end{tabular}

\subsubsection{MtPknB (PDB ID: 2FUM)}

The choice of drug to target the MtPknB protein is decarine. Decarine showed a docking score of $-9.7 \mathrm{kcal} / \mathrm{mol}$ which was lower than the standard MIX score $(-10.8 \mathrm{Kcal} / \mathrm{mol})$. Additionally, Decarine formed hydrophobic bonds and hydrophobic bonds which has importance for a ligand, as previously discussed. Thus, decarine is an ideal candidate for further studies.

Table 14-Physiochemical properties of the standard and proposed drug

\begin{tabular}{|l|l|l|}
\hline Property Name & Property Value TLM & $\begin{array}{l}\text { Property Value } \\
\text { Shermilamine B }\end{array}$ \\
\hline Molecular Weight & $444.488 \mathrm{~g} / \mathrm{mol}$ & $319.316 \mathrm{~g} / \mathrm{mol}$ \\
\hline XLogP3-AA & 1 & 4.1 \\
\hline Hydrogen Bond Donor Count & 8 & 1 \\
\hline Hydrogen Bond Acceptor & 10 & 5 \\
\hline Count & & 1 \\
\hline Rotatable Bond Count & 12 & $319.084 \mathrm{~g} / \mathrm{mol}$ \\
\hline Exact Mass & & \\
\hline
\end{tabular}




\begin{tabular}{|l|l|l|}
\hline Monoisotopic Mass & $444.201 \mathrm{~g} / \mathrm{mol}$ & $319.084 \mathrm{~g} / \mathrm{mol}$ \\
\hline Topological Polar Surface & $163 \mathrm{~A}^{\wedge} 2$ & $60.8 \mathrm{~A}^{\wedge} 2$ \\
\hline Heavy Atom Count & 32 & 24 \\
\hline
\end{tabular}

The physiochemical properties of the proposed drug and the standard drug obtained from PubChem(Kim et al., 2016) are given below for comparison :

The predicted ADMET properties (Absorption, Distribution, Metabolism, Excretion, Toxicity) properties are given below for the help of future lead optimization. ADMETSAR 2.0, an online tool, was used to do this.(H. Yang et al., 2019). The green indicates that these value are in range for the parameter and the red indicates these values are out of the range for the parameter.

Table 15:ADMET properties of the standard and proposed drug

\begin{tabular}{|l|lr|l|l|l|}
\hline ADMET & Value for & Probability for & Value for & Probability of \\
properties & standard drug & standard drug & decarine & decarine \\
\hline MIX & + & MIX & & \\
Intestinal & & 0.9760 & + & 0.9874 \\
\hline $\begin{array}{l}\text { Caco-2 } \\
\text { Blood }\end{array}$ & - & & & & \\
\hline Barrier & + & 0.8827 & + & 0.6609 \\
\hline Human & & 0.8908 & + & 0.9404 \\
bioavailability & acceptable & acceptable & Not acceptable & Not acceptable \\
\hline
\end{tabular}




\begin{tabular}{|c|c|c|c|c|}
\hline $\begin{array}{l}\text { P-glycoprotein } \\
\text { inhibitior }\end{array}$ & - & 0.8566 & - & 0.7562 \\
\hline $\begin{array}{l}\text { Carcinogenicity } \\
\text { (binary) }\end{array}$ & $\begin{array}{l}- \\
\text { acceptable }\end{array}$ & $\begin{array}{l}0.7317 \\
\text { acceptable }\end{array}$ & $\begin{array}{l}- \\
\text { acceptable }\end{array}$ & $\begin{array}{l}0.9286 \\
\text { acceptable }\end{array}$ \\
\hline $\begin{array}{l}\text { Carcinogenicity } \\
\text { (trinary) }\end{array}$ & $\begin{array}{l}\text { Non-required } \\
\text { acceptable }\end{array}$ & $\begin{array}{l}0.7325 \\
\text { acceptable }\end{array}$ & $\begin{array}{l}\text { Non-required } \\
\text { acceptable }\end{array}$ & $\begin{array}{l}0.4096 \\
\text { acceptable }\end{array}$ \\
\hline $\begin{array}{l}\text { Ames } \\
\text { mutagenesis }\end{array}$ & +Not acceptable & $\begin{array}{l}0.9900 \\
\text { Not acceptable }\end{array}$ & $\begin{array}{l}+ \\
\text { Not acceptable }\end{array}$ & $\begin{array}{l}0.6400 \\
\text { Not acceptable }\end{array}$ \\
\hline $\begin{array}{l}\text { Human either-a- } \\
\text { go-go inhibition }\end{array}$ & - acceptable & $\begin{array}{l}0.5836 \\
\text { acceptable }\end{array}$ & - acceptable & $\begin{array}{l}0.6964 \\
\text { acceptable }\end{array}$ \\
\hline $\begin{array}{l}\text { CYP inhibitory } \\
\text { promiscuity }\end{array}$ & - & 0.9211 & + & 0.8323 \\
\hline $\begin{array}{l}\text { Acute Oral } \\
\text { Toxicity (c) }\end{array}$ & III & 0.7527 & III & 0.7061 \\
\hline
\end{tabular}

\subsubsection{MtPanK (PDB ID: 4BFT)}

The choice of drug to target the MtPanK protein is Brachystamide B. Brachystamide B showed a docking score of $-8.6 \mathrm{kcal} / \mathrm{mol}$ which was higher than the standard ZVT score. $(-7$. Kcal /mol). Additionally, Brachystamide B formed only hydrophobic bonds and hydrophobic bonds which has importance for a ligand, as previously discussed. Thus, brachystamide B is an ideal candidate for further studies.

The physiochemical properties of the proposed drug and the standard drug obtained from pubchem(Kim et al., 2016) are given below for comparison 
Table 16: Physiochemical properties of the standard and proposed drug

\begin{tabular}{|l|l|l|}
\hline Property Name & Property Value ZVT & Property Value \\
& & Brachystamide B \\
\hline Molecular Weight & $434.914 \mathrm{~g} / \mathrm{mol}$ & $411.586 \mathrm{~g} / \mathrm{mol}$ \\
\hline XLogP3-AA & 3.9 & 7.9 \\
\hline Hydrogen Bond Donor Count & 1 & 1 \\
\hline Hydrogen Bond Acceptor & 6 & 3 \\
\hline Count & & 14 \\
\hline Rotatable Bond Count & 8 & $411.277 \mathrm{~g} / \mathrm{mol}$ \\
\hline Exact Mass & & $411.277 \mathrm{~g} / \mathrm{mol}$ \\
\hline Area & $434.098 \mathrm{~g} / \mathrm{mol}$ & \\
\hline Heavy Atom Count & 29 & $47.6 \mathrm{~A} 2$ \\
\hline Monoisotopic Mass & $434.098 \mathrm{~g} / \mathrm{mol}$ & \\
\hline & $94.3 \mathrm{~A} 22$ & \\
\hline
\end{tabular}

The predicted ADMET properties (Absorption, Distribution, Metabolism, Excretion, Toxicity) properties are given below for the help of future lead optimization. ADMETSAR 2.0, an online tool, was used to do this.(H. Yang et al., 2019).The green indicates that these value are in range for the parameter and the red indicates these values are out of the range for the parameter. 
Table 17: ADMET properties of the standard and proposed drug

\begin{tabular}{|c|c|c|c|c|}
\hline $\begin{array}{l}\text { ADMET } \\
\text { properties }\end{array}$ & $\begin{array}{l}\text { Value for } \\
\text { standard drug } \\
\text { ZVT }\end{array}$ & $\begin{array}{l}\text { Probability for } \\
\text { standard drug } \\
\text { ZVT }\end{array}$ & $\begin{array}{l}\text { Value for } \\
\text { Brachystamide } \\
\text { B }\end{array}$ & $\begin{array}{l}\text { Probability of } \\
\text { Brachystamide } \\
\text { B }\end{array}$ \\
\hline $\begin{array}{l}\text { Human } \\
\text { Intestinal } \\
\text { Absorption }\end{array}$ & + & 0.9127 & + & 0.9771 \\
\hline Caco-2 & - & 0.6657 & - & 0.6480 \\
\hline $\begin{array}{l}\text { Blood Brain } \\
\text { Barrier }\end{array}$ & + & 0.9769 & + & 0.9811 \\
\hline $\begin{array}{l}\text { Human oral } \\
\text { bioavailability }\end{array}$ & - Not acceptable & $\begin{array}{l}0.5571 \\
\text { Not acceptable }\end{array}$ & - Not acceptable & $\begin{array}{l}0.6286 \\
\text { Not acceptable }\end{array}$ \\
\hline $\begin{array}{l}\text { P-glycoprotein } \\
\text { inhibitior }\end{array}$ & + & 0.7317 & + & 0.8162 \\
\hline $\begin{array}{l}\text { Carcinogenicity } \\
\text { (binary) }\end{array}$ & - acceptable & $\begin{array}{l}0.7908 \\
\text { acceptable }\end{array}$ & - acceptable & $\begin{array}{l}0.9429 \\
\text { acceptable }\end{array}$ \\
\hline $\begin{array}{l}\text { Carcinogenicity } \\
\text { (trinary) }\end{array}$ & $\begin{array}{l}\text { Non-required } \\
\text { acceptable }\end{array}$ & $\begin{array}{l}0.4752 \\
\text { acceptable }\end{array}$ & $\begin{array}{l}\text { Non-required } \\
\text { acceptable }\end{array}$ & $\begin{array}{l}0.5911 \\
\text { acceptable }\end{array}$ \\
\hline $\begin{array}{l}\text { Ames } \\
\text { mutagenesis }\end{array}$ & - & $\begin{array}{l}0.6900 \\
\text { acceptable }\end{array}$ & $\begin{array}{l}- \\
\text { acceptable }\end{array}$ & $\begin{array}{l}0.8400 \\
\text { acceptable }\end{array}$ \\
\hline $\begin{array}{l}\text { Human either-a- } \\
\text { go-go inhibition }\end{array}$ & $\begin{array}{l}+ \\
\text { Not acceptable }\end{array}$ & $\begin{array}{l}0.7981 \\
\text { Not acceptable }\end{array}$ & $\begin{array}{l}+ \\
\text { Not acceptable }\end{array}$ & $\begin{array}{l}0.7710 \\
\text { Not acceptable }\end{array}$ \\
\hline $\begin{array}{l}\text { CYP inhibitory } \\
\text { promiscuity }\end{array}$ & + & 0.9093 & + & 0.7623 \\
\hline
\end{tabular}




\begin{tabular}{|l|l|l|l|l|}
\hline Acute Oral & III & 0.5701 & 0.6716 & III \\
Toxicity (c) & & & & \\
\hline
\end{tabular}

\subsubsection{MtDprE1 (PDB ID: 4FF6)}

The choice of drug to target the MtDprE1 protein is monoamphilectine A. Monoamphilcetine A showed a docking score of $-9.8 \mathrm{kcal} / \mathrm{mol}$ which was higher than the standard OT4 score. (9.2kcal $/ \mathrm{mol}$ ). Additionally, Brachystamide B formed only hydrophobic bonds and hydrophobic bonds which has importance for a ligand, as previously discussed. Thus, brachystamide B is an ideal candidate for further studies.

The physiochemical properties of the proposed drug and the standard drug obtained from pubchem(Kim et al., 2016) are given below for /comparison

Table 18: Physiochemical properties of the standard and proposed drug

\begin{tabular}{|l|l|l|}
\hline Property Name & Property Value ZVT & Property Value \\
\hline Molecular Weight & $434.914 \mathrm{~g} / \mathrm{mol}$ & $411.586 \mathrm{~g} / \mathrm{mol}$ \\
\hline XLogP3-AA & 3.9 & 7.9 \\
\hline Hydrogen Bond Donor Count & 1 & 1 \\
\hline Hydrogen Bond Acceptor & 6 & 3 \\
\hline Count & & 14 \\
\hline Rotatable Bond Count & 8 & $411.277 \mathrm{~g} / \mathrm{mol}$ \\
\hline & $434.098 \mathrm{~g} / \mathrm{mol}$ & \\
\hline & & \\
\hline
\end{tabular}




\begin{tabular}{|l|l|l|}
\hline Monoisotopic Mass & $434.098 \mathrm{~g} / \mathrm{mol}$ & $411.277 \mathrm{~g} / \mathrm{mol}$ \\
\hline Topological Polar Surface & $94.3 \mathrm{~A}^{\wedge} 2$ & $47.6 \mathrm{~A}^{\wedge} 2$ \\
\hline Heavy Atom Count & 29 & 30 \\
\hline
\end{tabular}

The predicted ADMET properties (Absorption, Distribution, Metabolism, Excretion, Toxicity) properties are given below for the help of future lead optimization. ADMETSAR 2.0, an online tool, was used to do this.(H. Yang et al., 2019) The green indicates that these value are in range for the parameter and the red indicates these values are out of the range for the parameter.

Table 19:Physiochemical properties of the standard and proposed drugs

\begin{tabular}{|l|l|l|l|l|}
\hline ADMET for & Probability for & Value for & Probability of \\
properties & standard drug & standard drug & Brachystamide & Brachystamide \\
ZVT & + & ZVT & B & B \\
\hline Intestinal & & 0.9127 & + & 0.9771 \\
Absorption & & & & \\
\hline Caco-2 & - & 0.6657 & - & 0.6480 \\
\hline Blood Brain & + & 0.9769 & + & 0.9811 \\
Barrier & & & & \\
\hline Human oral & - & 0.5571 & & \\
\hline bioavailability & Not acceptable & Not acceptable & Not acceptable & Not acceptable \\
\hline P-glycoprotein & + & 0.7317 & + & 0.8162 \\
inhibitior & & & & \\
\hline
\end{tabular}




\begin{tabular}{|l|l|l|l|l|}
\hline Carcinogenicity & - & 0.7908 & - & 0.9429 \\
(binary) & acceptable & acceptable & acceptable & acceptable \\
\hline $\begin{array}{l}\text { Carcinogenicity } \\
\text { trinary) }\end{array}$ & Non-required & 0.4752 & Non-required & 0.5911 \\
\hline $\begin{array}{l}\text { Ames } \\
\text { mutagenesis }\end{array}$ & acceptable & acceptable & acceptable & acceptable \\
\hline Human either-a- & + & 0.6900 & - & 0.8400 \\
go-go inhibition & Not acceptable & Not acceptable & Not acceptable & Not acceptable \\
\hline CYP inhibitory & + & 0.9093 & + & acceptable \\
promiscuity & & 0.7981 & & 0.7623 \\
\hline Acute Oral \\
Toxicity (c)
\end{tabular}




\section{Chapter 4}

\section{Discussion}

MtKasA, MtPanK, MtPknB and MtDprE1 are proteins, which are essential for the growth, pathogenicity and survival of mycobacterium tuberculosis. As a major controller of the developmental processes in tuberculosis, these proteins can be considered therapeutic targets (Awasthy et al., 2010; Kang et al., 2005; Mikusová et al., 2014; Sassetti et al., 2003). TB is one of the leading causes of death due to infectious diseases in the world and due to the increase of resistant species current drugs are not enough to combat this disease (World Health Organisation, 2018). Therefore, newer drugs are required to treat tuberculosis clinically. For this purpose, using computational techniques for discovery of new drugs can be employed (Lobanov, 2004). Molecular docking can also be employed as a computational technique (Guedes, de Magalhães, \& Dardenne, 2014).

After doing an extensive review on proteins associated with tuberculosis, tuberculosis and computational techniques this study was designed to find out some potential drugs to inhibit key proteins associated with the survival of M. Tuberculosis. More than 150 random chemical constituents derived from natural sources of different classes were screened for this study. For this screening purpose, molecular docking was used among other in silico techniques.

Throughout the study, several in silico techniques were used. To begin with, obtaining and validating the 3D structure of the target protein MtKasA,MtPanK, MtPknB and MtDpre1 RCSB PDB was used (Berman et al., 2000). The 3D structure of the target protein was found to be valid and suitable after observing the outcome of ProSA Web Server and PROSESS( Berjanskii et al., 2010; Wiederstein \& Sippl, 2007). 150 chemical constituents of different class were screened via docking and of them alkaloid showed potential as drugs. Four of those drugs namely shermilamine B, brachystamide B, decarine and monoamphilectine A. Four inhibitors 
that were bound to the target proteins as inhibitors were also chosen for validation. They are ZVT, TLM, MIX and OT4.

The binding affinities of drugs of alkaloids after rigid docking using autodock Vina were found between $-8.5 \mathrm{kcal} / \mathrm{mol}$ to $-9.8 \mathrm{kcal} / \mathrm{mol}$ which represents a strong binding affinity. The binding affinities of the established inhibitors were also calculated using same method. The results of their binding affinities were higher for three of the target proteins (MtKasA, MtPanK, MtDprE1 and lower for one (MtPknB). Therefore, it is clear that the chosen drugs have stronger affinity towards the target proteins and can be used as potential leads.

After visualizing using PyMOL, it was found out that the alkaloid constituents and established inhibitors bind within a same pocket in the target proteins. Ramachandran Plot analysis, for all the protein-ligand complexes were found same.

In order to know the protein-ligand interactions of all the ligands with proteins, Discovery Studio Visualizer was used. Bonds formed between these amino acids of proteins and ligands were also shown. It helped to compare and contrast the protein-ligand interactions of both proposed leads and proteins and established inhibitors and proteins. Based on interaction studies it can be seen that strong bonds such as hydrogen bonds and pi cation and pi aninon bonds featured significantly in the results proving that these ligands can be potential drugs in the future namely MtDprE1 can be targeted using monoamhilectine A, MtKasA can be targeted using shermilamine B,MtPknB can be targeted using decarine and MtPanK can be targeted using brachystamide B. 


\section{Chapter 5}

\section{Conclusion}

The study evaluated the efficiency of the choice of chemical constituents from natural sources, to be used in tuberculosis treatment as inhibitors of four proteins. It was done by using several efficient in silico approaches. The findings of these in silico approaches provide a clear and distinct concept about the efficiency of the established inhibitors working by interacting with targeted proteins. On the other hand, Decarine, the selected lead among drugs of different classes exhibited best binding affinity and strong protein-ligand interactions with MtPKnB protein, Brachystamide B the selected lead among drugs of different classes exhibited best binding affinity and strong protein-ligand interactions with MtPanK protein, Monoamphilcetine A the selected lead among drugs of different classes exhibited best binding affinity and strong protein-ligand interactions with MtDprE1 protein and shermilamine $\mathrm{B}$, the selected lead among drugs of different classes exhibited best binding affinity and strong protein-ligand interactions with MtKasA protein . The results showed a promising future for these leads as potent antiTB drugs. 


\section{Chapter 6}

\section{Future work}

To evaluate the docking predictions and concrete evidences to gain widespread acceptance,

further study of these drugs and protein should be carried out along with in vivo and in vitro studies. 


\section{References}

Alberg, D. G., \& Schreiber, S. L. (1993). Structure-based design of a cyclophilin-calcineurin bridging ligand. Science (New York, N.Y.), 262(5131), 248-250. Retrieved from http://www.ncbi.nlm.nih.gov/pubmed/8211144

Appleton, D. R., Pearce, A. N., \& Copp, B. R. (2010). anti-Tuberculosis natural products: synthesis and biological evaluation of pyridoacridine alkaloids related to ascididemin. Tetrahedron, 66(27-28), 4977-4986.

Avilés, E., \& Rodríguez, A. D. (2010). Monamphilectine A, a Potent Antimalarial $\beta$-Lactam from Marine Sponge Hymeniacidon sp: Isolation, Structure, Semisynthesis, and Bioactivity. Organic Letters, 12(22), 5290-5293.

Awasthy, D., Ambady, A., Bhat, J., Sheikh, G., Ravishankar, S., Subbulakshmi, V., ... Sharma, U. (2010). Essentiality and functional analysis of type I and type III pantothenate kinases of Mycobacterium tuberculosis. Microbiology, 156(9), 2691-2701.

Barry, C. E., Lee, R. E., Mdluli, K., Sampson, A. E., Schroeder, B. G., Slayden, R. A., \& Yuan, Y. (1998). Mycolic acids: structure, biosynthesis and physiological functions. Progress in Lipid Research, 37(2-3), 143-179. Retrieved from http://www.ncbi.nlm.nih.gov/pubmed/9829124

Batt, S. M., Jabeen, T., Bhowruth, V., Quill, L., Lund, P. A., Eggeling, L., ... Besra, G. S. (2012). Structural basis of inhibition of Mycobacterium tuberculosis DprE1 by benzothiazinone inhibitors. Proceedings of the National Academy of Sciences of the United States of America, 109(28), 11354-11359.

Berjanskii, M., Liang, Y., Zhou, J., Tang, P., Stothard, P., Zhou, Y., ... Wishart, D. S. (2010). PROSESS: a protein structure evaluation suite and server. Nucleic Acids Research, 
38(Web Server), W633-W640.

Berman, H. M., Westbrook, J., Feng, Z., Gilliland, G., Bhat, T. N., Weissig, H., ... Bourne, P. E. (2000). The Protein Data Bank. Nucleic Acids Research, 28(1), 235-242.

Bhatt, A., Kremer, L., Dai, A. Z., Sacchettini, J. C., \& Jacobs, W. R. (2005). Conditional Depletion of KasA, a Key Enzyme of Mycolic Acid Biosynthesis, Leads to Mycobacterial Cell Lysis. Journal of Bacteriology, 187(22), 7596-7606.

Björkelid, C., Bergfors, T., Raichurkar, A. K. V, Mukherjee, K., Malolanarasimhan, K., Bandodkar, B., \& Jones, T. A. (2013). Structural and biochemical characterization of compounds inhibiting Mycobacterium tuberculosis pantothenate kinase. The Journal of Biological Chemistry, 288(25), 18260-18270.

Bloom, B. R., Atun, R., Cohen, T., Dye, C., Fraser, H., Gomez, G. B., ... Yadav, P. (2017). Tuberculosis. Retrieved from https://researchonline.lshtm.ac.uk/4647323/1/Tuberculosis Disease Control Priorities GOLD VoR.pdf

Boitel, B., Ortiz-Lombardía, M., Durán, R., Pompeo, F., Cole, S. T., Cerveñansky, C., \& Alzari, P. M. (2003). PknB kinase activity is regulated by phosphorylation in two Thr residues and dephosphorylation by PstP, the cognate phospho-Ser/Thr phosphatase, in Mycobacterium tuberculosis. Molecular Microbiology, 49(6), 1493-1508. Retrieved from http://www.ncbi.nlm.nih.gov/pubmed/12950916

Brand, L. A., \& Strauss, E. (2005). Characterization of a New Pantothenate Kinase Isoform from Helicobacter pylori. Journal of Biological Chemistry, 280(21), 20185-20188.

Campbell, J. W., \& Cronan, J. E. (2001). Bacterial Fatty Acid Biosynthesis: Targets for Antibacterial Drug Discovery. Annual Review of Microbiology, 55(1), 305-332.

Chang, J., Kim, Y., \& Kwon, H. J. (2016). Advances in identification and validation of protein 
targets of natural products without chemical modification. Natural Product Reports, 33(5), 719-730. Cohen, N. R., Lobritz, M. A., \& Collins, J. J. (2013). Microbial Persistence and the Road to Drug Resistance. Cell Host \& Microbe, 13(6), 632-642.

Daffé, M., \& Draper, P. (1998). The envelope layers of mycobacteria with reference to their pathogenicity. Advances in Microbial Physiology, 39, 131-203. Retrieved from http://www.ncbi.nlm.nih.gov/pubmed/9328647

Dashti, Y., Grkovic, T., \& Quinn, R. J. (2014). Predicting natural product value, an exploration of anti-TB drug space. Natural Product Reports, 31(8), 990-998.

Dassault Systèmes BIOVIA. (2010). Discovery Studio Visualizer. Technology.

Davis, A. M., \& Teague, S. J. (1997). Hydrogen Bonding, Hydrophobic Interactions, and Failure of the Rigid Receptor Hypothesis.

DeLano, W. L. (2002). PyMOL: An open-source molecular graphics tool. CCP4 Newsletter On Protein Crystallography, 40, 82-92.

Dunn, S. D., \& Snell, E. E. (1979). Isolation of temperature-sensitive pantothenate kinase mutants of Salmonella typhimurium and mapping of the coaA gene. Journal of Bacteriology, $\quad$ 140(3), $\quad 805-808 . \quad$ Retrieved from http://www.ncbi.nlm.nih.gov/pubmed/230178

Geer, L. Y., Marchler-Bauer, A., Geer, R. C., Han, L., He, J., He, S., .. Bryant, S. H. (2009). The NCBI BioSystems database. Nucleic Acids Research, 38(SUPPL.1), 492-496.

Global tuberculosis report. (2014). $\quad$ Retrieved from https://www.who.int/tb/publications/global_report/gtbr14_main_text.pdf

Goodsell, D. S., Morris, G. M., \& Olson, A. J. (n.d.). Automated docking of flexible ligands: applications of AutoDock. Journal of Molecular Recognition: JMR, 9(1), 1-5. 
https://doi.org/10.1002/(SICI)1099-1352(199601)9:1\%3C1::AID-

JMR241\%3E3.0.CO;2-6

Guedes, I. A., de Magalhães, C. S., \& Dardenne, L. E. (2014). Receptor-ligand molecular docking. Biophysical Reviews, 6(1), 75-87.

HARVEY, A. (2008). Natural products in drug discovery. Drug Discovery Today, 13(19-20), 894-901.

Harvey, A. L., Clark, R. L., Mackay, S. P., \& Johnston, B. F. (2010). Current strategies for drug discovery through natural products. Expert Opinion on Drug Discovery, 5(6), 559568.

Hunter, T. (2000). Signaling--2000 and beyond. Cell, 100(1), 113-127. Retrieved from http://www.ncbi.nlm.nih.gov/pubmed/10647936

Isaka, M., Boonkhao, B., Rachtawee, P., \& Auncharoen, P. (2007). A Xanthocillin-like Alkaloid from the Insect Pathogenic Fungus Cordyceps brunnearubra BCC 1395. Journal of Natural Products, 70(4), 656-658.

Jackowski, S., \& Rock, C. O. (1981). Regulation of coenzyme A biosynthesis. Journal of $\begin{array}{llll}\text { Bacteriology, } & \text { 148(3), } & \text { 926-932. } & \text { Retrieved }\end{array}$ http://www.ncbi.nlm.nih.gov/pubmed/6796563

Källblad, P., Mancera, R. L., \& Todorov, N. P. (2004). Assessment of Multiple Binding Modes in Ligand-Protein Docking. Journal of Medicinal Chemistry, 47(13), 3334-3337.

Kana, B. D., Karakousis, P. C., Parish, T., \& Dick, T. (2014). Future target-based drug discovery for tuberculosis? Tuberculosis (Edinburgh, Scotland), 94(6), 551-556.

Kang, C.-M., Abbott, D. W., Park, S. T., Dascher, C. C., Cantley, L. C., \& Husson, R. N. (2005). The Mycobacterium tuberculosis serine/threonine kinases PknA and PknB: 
substrate identification and regulation of cell shape. Genes \& Development, 19(14), 16921704.

Kaur, D., Mathew, S., Nair, C. G. S., Begum, A., Jainanarayan, A. K., Sharma, M., \& Brahmachari, S. K. (2017). Structure based drug discovery for designing leads for the non-toxic metabolic targets in multi drug resistant Mycobacterium tuberculosis. Journal of Translational Medicine, 15(1), 261.

Kim, S., Thiessen, P. A., Bolton, E. E., Chen, J., Fu, G., Gindulyte, A., ... Bryant, S. H. (2016). PubChem Substance and Compound databases. Nucleic Acids Research, 44(D1), D120213.

Koul, A., Arnoult, E., Lounis, N., Guillemont, J., \& Andries, K. (2011). The challenge of new drug discovery for tuberculosis. Nature, 469(7331), 483-490.

Kremer, L., Dover, L. G., Carrère, S., Nampoothiri, K. M., Lesjean, S., Brown, A. K., ... Besra, G. S. (2002). Mycolic acid biosynthesis and enzymic characterization of the betaketoacyl-ACP synthase A-condensing enzyme from Mycobacterium tuberculosis. The Biochemical Journal, 364(Pt 2), 423-430.

Kremer, L., Dover, L. G., Morbidoni, H. R., Vilchèze, C., Maughan, W. N., Baulard, A., ... Besra, G. S. (2003). Inhibition of InhA Activity, but Not KasA Activity, Induces Formation of a KasA-containing Complex in Mycobacteria. Journal of Biological Chemistry, 278(23), 20547-20554.

Leonardi, R., Chohnan, S., Zhang, Y.-M., Virga, K. G., Lee, R. E., Rock, C. O., \& Jackowski, S. (2005). A Pantothenate Kinase from Staphylococcus aureus Refractory to Feedback Regulation by Coenzyme A. Journal of Biological Chemistry, 280(5), 3314-3322.

Li, Q., Cheng, T., Wang, Y., \& Bryant, S. H. (2010). PubChem as a public resource for drug 
discovery. Drug Discovery Today, 15(23-24), 1052-1057.

Lietava, J. (1992). Medicinal plants in a Middle Paleolithic grave Shanidar IV? Journal of Ethnopharmacology, 35(3), 263-266. Retrieved from

Limongelli, V., Marinelli, L., Cosconati, S., Braun, H. A., Schmidt, B., \& Novellino, E. (2007). Ensemble-Docking Approach on BACE-1: Pharmacophore Perception and Guidelines for Drug Design. ChemMedChem, 2(5), 667-678.

Lobanov, V. (2004). Using artificial neural networks to drive virtual screening of combinatorial libraries. Drug Discovery Today: BIOSILICO, 2(4), 149-156.

Lu, Y.-J., Zhang, Y.-M., \& Rock, C. O. (2004). Product diversity and regulation of type II fatty acid synthases. Biochemistry and Cell Biology, 82(1), 145-155.

Luckner, S. R., Machutta, C. A., Tonge, P. J., \& Kisker, C. (2009). Crystal Structures of Mycobacterium tuberculosis KasA Show Mode of Action within Cell Wall Biosynthesis and its Inhibition by Thiolactomycin. Structure, 17(7), 1004-1013.

Luo, X., Pires, D., Aínsa, J. A., Gracia, B., Duarte, N., Mulhovo, S., ... Ferreira, M.-J. U. (2013). Zanthoxylum capense constituents with antimycobacterial activity against Mycobacterium tuberculosis in vitro and ex vivo within human macrophages. Journal of Ethnopharmacology, 146(1), 417-422.

Manjunatha, U. H., \& Smith, P. W. (2015). Perspective: Challenges and opportunities in TB drug discovery from phenotypic screening. Bioorganic \& Medicinal Chemistry, 23(16), $5087-5097$.

Mdluli, K., Kaneko, T., \& Upton, A. (2014). Tuberculosis drug discovery and emerging targets. Annals of the New York Academy of Sciences, 1323(1), 56-75. https://doi.org/10.1111/nyas.12459 
Mikusová, K., Makarov, V., \& Neres, J. (2014). DprE1--from the discovery to the promising tuberculosis drug target. Current Pharmaceutical Design, 20(27), 4379-4403. Retrieved from http://www.ncbi.nlm.nih.gov/pubmed/24245764

Mishra, B. B., \& Tiwari, V. K. (2011). Natural products: An evolving role in future drug discovery. European Journal of Medicinal Chemistry, 46(10), 4769-4807. https://doi.org/10.1016/J.EJMECH.2011.07.057

Mishra, S. K., Tripathi, G., Kishore, N., Singh, R. K., Singh, A., \& Tiwari, V. K. (2017). Drug development against tuberculosis: Impact of alkaloids. European Journal of Medicinal Chemistry, 137, 504-544. https://doi.org/10.1016/j.ejmech.2017.06.005

Morris, G. M., Huey, R., Lindstrom, W., Sanner, M. F., Belew, R. K., Goodsell, D. S., \& Olson, A. J. (2009). AutoDock4 and AutoDockTools4: Automated docking with selective receptor flexibility. Journal of Computational Chemistry, 30(16), 2785-2791. https://doi.org/10.1002/jcc.21256

Moses, H., Dorsey, E. R., Matheson, D. H. M., \& Thier, S. O. (2005). Financial Anatomy of Biomedical Research. JAMA, 294(11), 1333. https://doi.org/10.1001/jama.294.11.1333

Munos, B. (2009). Lessons from 60 years of pharmaceutical innovation. Nature Reviews Drug Discovery, 8(12), 959-968. https://doi.org/10.1038/nrd2961

Myers, S., \& Baker, A. (2001). Drug discovery — an operating model for a new era. Nature Biotechnology, 19(8), 727-730. https://doi.org/10.1038/90765

O’Boyle, N. M., Banck, M., James, C. A., Morley, C., Vandermeersch, T., \& Hutchison, G. R. (2011). Open Babel: An open chemical toolbox. Journal of Cheminformatics, 3(1), 33.

Ou-Yang, S.-S., Lu, J.-Y., Kong, X.-Q., Liang, Z.-J., Luo, C., \& Jiang, H. (2012). Computational drug discovery. Acta Pharmacologica Sinica, 33(9), 1131-1140. 
Patil, R., Das, S., Stanley, A., Yadav, L., Sudhakar, A., \& Varma, A. K. (2010). Optimized hydrophobic interactions and hydrogen bonding at the target-ligand interface leads the pathways of drug-designing. PloS One, 5(8), e12029.

Paulson, T. (2013). Epidemiology: A mortal foe. Nature, 502(7470), S2-S3.

RAMPAGE: Ramachandran Plot Assessment. (n.d.). Retrieved May 20, 2019, from

Rock, C. O., Karim, M. A., Zhang, Y.-M., \& Jackowski, S. (2002). The murine pantothenate kinase (Pank1) gene encodes two differentially regulated pantothenate kinase isozymes. Gene, 291(1-2), 35-43. Retrieved from http://www.ncbi.nlm.nih.gov/pubmed/12095677

Sassetti, C. M., Boyd, D. H., \& Rubin, E. J. (2003). Genes required for mycobacterial growth defined by high density mutagenesis. Molecular Microbiology, 48(1), 77-84. Retrieved from http://www.ncbi.nlm.nih.gov/pubmed/12657046

Seung, K. J., Keshavjee, S., \& Rich, M. L. (2015). Multidrug-Resistant Tuberculosis and Extensively Drug-Resistant Tuberculosis. Cold Spring Harbor Perspectives in Medicine, 5(9), a017863.

Shekhar, C. (2008). In Silico Pharmacology: Computer-Aided Methods Could Transform Drug Development. Chemistry \& Biology, 15(5), 413-414.

Smith, S., Witkowski, A., \& Joshi, A. K. (2003). Structural and functional organization of the animal fatty acid synthase. Progress in Lipid Research, 42(4), 289-317. Retrieved from http://www.ncbi.nlm.nih.gov/pubmed/12689621

Song, W. J., \& Jackowski, S. (1994). Kinetics and regulation of pantothenate kinase from Escherichia coli. The Journal of Biological Chemistry, 269(43), 27051-27058. Retrieved from http://www.ncbi.nlm.nih.gov/pubmed/7929447

Trott, O., \& Olson, A. J. (2010). AutoDock Vina: improving the speed and accuracy of docking 
with a new scoring function, efficient optimization, and multithreading. Journal of Computational Chemistry, 31(2), 455-461.

Tuberculosis. (2018). Retrieved May 25, 2019, from https://www.who.int/news-room/factsheets/detail/tuberculosis

Vallari, D. S., Jackowski, S., \& Rock, C. O. (1987). Regulation of pantothenate kinase by coenzyme A and its thioesters. The Journal of Biological Chemistry, 262(6), 2468-2471. Retrieved from http://www.ncbi.nlm.nih.gov/pubmed/3029083

Veyron-Churlet, R., Bigot, S., Guerrini, O., Verdoux, S., Malaga, W., Daffé, M., \& Zerbib, D. (2005). The Biosynthesis of Mycolic Acids in Mycobacterium tuberculosis Relies on Multiple Specialized Elongation Complexes Interconnected by Specific Protein-Protein Interactions. Journal of Molecular Biology, 353(4), 847-858.

Veyron-Churlet, R., Guerrini, O., Mourey, L., Daffé, M., \& Zerbib, D. (2004). Protein-protein interactions within the Fatty Acid Synthase-II system of Mycobacterium tuberculosis are essential for mycobacterial viability. Molecular Microbiology, 54(5), 1161-1172.

Villarino, A., Duran, R., Wehenkel, A., Fernandez, P., England, P., Brodin, P., ... Alzari, P. M. (2005). Proteomic Identification of M.tuberculosis Protein Kinase Substrates: PknB Recruits GarA, a FHA Domain-containing Protein, Through Activation Loop-mediated Interactions. Journal of Molecular Biology, 350(5), 953-963.

Wehenkel, A., Fernandez, P., Bellinzoni, M., Catherinot, V., Barilone, N., Labesse, G., ... Alzari, P. M. (2006). The structure of PknB in complex with mitoxantrone, an ATPcompetitive inhibitor, suggests a mode of protein kinase regulation in mycobacteria. FEBS Letters, 580(13), 3018-3022.

Weng, J.-K., Philippe, R. N., \& Noel, J. P. (2012). The Rise of Chemodiversity in Plants. 
Science, 336(6089), 1667-1670.

Wiederstein, M., \& Sippl, M. J. (2007). ProSA-web: interactive web service for the recognition of errors in three-dimensional structures of proteins. Nucleic Acids Research, 35(Web Server), W407-W410.

Wishart, D. S., Feunang, Y. D., Guo, A. C., Lo, E. J., Marcu, A., Grant, J. R., ... Wilson, M. (2018a). DrugBank 5.0: a major update to the DrugBank database for 2018. Nucleic Acids Research, 46(D1), D1074-D1082.

Wishart, D. S., Feunang, Y. D., Guo, A. C., Lo, E. J., Marcu, A., Grant, J. R., ... Wilson, M. (2018b). DrugBank 5.0: a major update to the DrugBank database for 2018. Nucleic Acids Research, 46(D1), D1074-D1082.

World Health Organisation. (2018). Global Health TB Report.

Yang, H., Lou, C., Sun, L., Li, J., Cai, Y., Wang, Z., ... Tang, Y. (2019). admetSAR 2.0: webservice for prediction and optimization of chemical ADMET properties. Bioinformatics, 35(6), 1067-1069.

Yang, K., Eyobo, Y., Brand, L. A., Martynowski, D., Tomchick, D., Strauss, E., \& Zhang, H. (2006). Crystal Structure of a Type III Pantothenate Kinase: Insight into the Mechanism of an Essential Coenzyme A Biosynthetic Enzyme Universally Distributed in Bacteria. Journal of Bacteriology, 188(15), 5532-5540.

Yuan, Y., Zhu, Y., Crane, D. D., \& Barry, C. E. (1998). The effect of oxygenated mycolic acid composition on cell wall function and macrophage growth in Mycobacterium tuberculosis. Molecular Microbiology, 29(6), 1449-1458. Retrieved from http://www.ncbi.nlm.nih.gov/pubmed/9781881

Yun, M., Park, C. G., Kim, J. Y., Rock, C. O., Jackowski, S., \& Park, H. W. (2000). Structural 
basis for the feedback regulation of Escherichia coli pantothenate kinase by coenzyme A. The Journal of Biological Chemistry, 275(36), 28093-28099.

Zaldini Hernandes, M., Melo Cavalcanti, S. T., Rodrigo Moreira, D. M., Filgueira de Azevedo Junior, W., \& Cristina Lima Leite, A. (2010). Halogen Atoms in the Modern Medicinal Chemistry: Hints for the Drug Design. Current Drug Targets, 11, 303-314. Retrieved from

https://www.researchgate.net/profile/Ana_Leite6/publication/41824147_Halogen_Atom s_in_the_Modern_Medicinal_Chemistry_Hints_for_the_Drug_Design/links/0c9605227a 9a638450000000.pdf

Zhang, Y., Post-Martens, K., \& Denkin, S. (2006). New drug candidates and therapeutic targets for tuberculosis therapy. Drug Discovery Today, 11(1-2), 21-27.

Zhou, B., Westaway, S. K., Levinson, B., Johnson, M. A., Gitschier, J., \& Hayflick, S. J. (2001). A novel pantothenate kinase gene (PANK2) is defective in Hallervorden-Spatz syndrome. Nature Genetics, 28(4), 345-349.

Zumla, A., Nahid, P., \& Cole, S. T. (2013). Advances in the development of new tuberculosis drugs and treatment regimens. Nature Reviews Drug Discovery, 12(5), 388-404. 
